\title{
Stated Preferences for Conservation Policies Under Uncertainty: Insights on the Effect of Individuals' Risk Attitudes in the Environmental Domain
}

\author{
Michela Faccioli $^{1,2}$ (D) Laure Kuhfuss $^{1,3} \cdot$ Mikołaj Czajkowski $^{4}$
}

Accepted: 17 July 2018 / Published online: 3 September 2018

(c) The Author(s) 2018

\begin{abstract}
The outcome of a conservation policy is often subject to uncertainty. In stated preference valuation, it is increasingly recognised that uncertainty affects preferences for the outcomes of environmental policies. However, there is also agreement that the effect of uncertainty and people's attitudes towards risk need to be better understood. To shed more light on the impact of risk, we designed a discrete choice experiment to compare preferences for environmental outcomes under climate change across two split samples. Each sample was confronted with a scenario where results were presented as certain or uncertain, but were otherwise associated with the same expected values. We found significant differences between the certain and the uncertain treatment, with uncertain outcomes being associated with more extreme utility levels and willingness to pay, in absolute terms. This finding was confirmed irrespective of whether gains or losses were considered and despite sensitivity to uncertainty-specific to the socio-demographic profile. Our results suggest that individuals are not risk neutral in the presence of uncertainty around environmental outcomes. These findings are crucial to better understand stated preferences for conservation policies in risky contexts. Our results reinforce the idea that uncertainty should be explicitly incorporated in the design of stated preference studies to better inform policy.
\end{abstract}

Keywords Stated preference valuation - Uncertainty $\cdot$ Risk attitude $\cdot$ Climate change . Conservation

Electronic supplementary material The online version of this article (https://doi.org/10.1007/s10640-018-0 276-2) contains supplementary material, which is available to authorized users.

Michela Faccioli

m.faccioli@exeter.ac.uk

1 Social, Economic and Geographical Sciences Research Group, The James Hutton Institute, Aberdeen AB15 8QH, UK

2 Present Address: Land, Environment, Economics and Policy Institute (LEEP), University of Exeter, Lazenby House, Prince of Wales Road, Exeter EX4 4PJ, UK

3 Department of Geography and Sustainable Development, University of St Andrews, Irvine Building, North Street, St. Andrews, Scotland KY16 9AL, UK

4 Department of Economics, University of Warsaw, Długa 44/50, 00-241 Warsaw, Poland 
JEL Codes D6 · D81 - Q20 - Q51 - Q54

\section{Introduction}

Risk and uncertainty are gaining increasing attention in the analysis of the social benefits of environmental policies. This is especially true within the stated preference (SP) valuation literature, which often deals with decisions under risk and uncertainty (e.g., preferences over environmental conservation). Several recent studies have shown that uncertainty around the results of environmental policies (due, for instance, to a limited understanding of a policy's technical performance or the social, economic and environmental context), significantly affects social preferences (e.g., Lundhede et al. 2015; Torres et al. 2017). It is therefore increasingly recommended to consider uncertainty in SP applications. If uncertainty is not explicitly considered in the design of the study, which has traditionally been the case within the valuation literature, the wrong conclusions about a policy's true social benefits will be drawn where respondents are not neutral to risk (Pindyck 2007). Although the treatment of risk within the field of SP has improved, researchers still argue that the effect of risk and uncertainty needs to be better understood to provide information that is more robust to policy-makers (Rolfe and Windle 2015).

To explore the role of uncertainty, previous SP literature (e.g. Roberts et al. 2008; Wielgus et al. 2009; Glenk and Colombo 2011) has compared the preferences of individuals for certain versus uncertain scenarios. These studies have generally defined uncertainty as the possibility that a given policy may not achieve a given outcome. Typically, this prior research has compared preferences in uncertain settings with those obtained in certain settings where the same policy outcome is definitely achieved. Following this approach, these studies have linked the introduction of uncertainty with a change (i.e. generally a decrease) in the expected payoffs relative to the certain case. In this context, a risky intervention will be perceived as less worthwhile than the certain counterpart because an uncertain policy can only achieve lower expected outcomes. As a result, this past literature has generally found that introducing uncertainty (regarding whether a policy will be able to achieve its target) decreases individuals' willingness to pay (WTP) for the policy.

Earlier economic theory (Rothschild and Stiglitz 1970) used a different approach to present risky alternatives. Similarly to the SP literature referred to above, these early authors presented a risky scenario as one displaying more uncertainty regarding the actual result, relative to a more certain scenario. However, in contrast to the SP literature referred to above, they also presented the uncertain scenario as one which had the same expected outcome as the certain scenario. This implied that a 'riskier' scenario could have both lower but also higher outcomes compared to a less risky scenario. Following this idea, individuals facing a 'riskier' scenario have to evaluate if they are prepared to take the risk of not knowing whether they potentially end up with a better or worse outcome relative to a certain scenario, in which, on average, the same expected result is offered with certainty (without taking any risk). We adopt this earlier approach to improve our understanding of how people react to uncertainty and, implicitly, to gain more insights into the attitudes of individuals towards risk. ${ }^{1}$ We compare

\footnotetext{
${ }^{1}$ How people react to risk per se (Ananda and Herath 2005; Andersson and Gong 2010; Caliendo et al. 2010) allows to classify them as risk averse, risk seekers or risk neutral (Schonberg et al. 2011; Riddel 2012). Individuals are risk averse if they display higher preferences for the certain rather than the uncertain case, despite expected outcomes are held constant. They are risk seekers if their preferences are higher for the uncertain prospect over the certain case or, in other words, if they appreciate more uncertainty (or higher variance) around equal expected payoffs. Alternatively, they are risk neutral if they are indifferent between the certain and uncertain scenarios (Wärneryd 1996).
} 
preferences between a certain and uncertain scenario, both displaying the same expected outcomes. By presenting individuals with the same expected environmental outcomes, on average, in the certain and uncertain scenarios, we allow only for the presence or absence of uncertainty (rather than a change in expected results) to drive possible differences in preferences. As the way people react to risk is expected to affect their preferences and behaviour, gaining an improved understanding of the role of risk within the SP literature is crucial to better inform public decision-makers about a policy's social return (Glenk and Colombo 2011).

Very few SP studies (e.g., Johansson 1989; Macmillan et al. 1996; Isik 2006; Koundouri et al. 2014; Larue et al. 2017) have managed to isolate the effect of uncertainty as described above and to explore its influence on individuals' willingness to pay (WTP). However, as we will describe in Sect. 2.1., these studies are also subject to some limitations. They have assumed that there is uncertainty either regarding the future environmental outcome with a policy change or regarding the future environmental outcome in the absence of a policy change (business as usual). However, in reality uncertainty simultaneously affects environmental outcomes under both scenarios. In addition, these studies have generally overlooked the fact that risk and uncertainty affect people's preferences in a heterogeneous way. Within the economics and psychology literature, there is a growing body of evidence showing that the way people react to risk depends on their socio-demographic characteristics and is domainspecific (Weber et al. 2002). This literature shows that attitudes towards risk depend on whether the risky decision concerns health, finance, recreation, social life, ethical or environmental issues. Attitudes to risk also depend on the nature of the good being assessed, the possible magnitude of the change (i.e. big or small) and the direction of the change (i.e. gain or loss) (Blais and Weber 2006; Pannenberg 2007; Dohmen et al. 2011; Figner and Weber 2011; Riddel 2012; Nguyen and Noussair 2014).

In this paper, we address the limitations of previous literature and apply a discrete choice experiment (DCE; Carson and Czajkowski, 2014; Hensher et al. 2015; Holmes et al. 2017) to gain a better understanding of the role of uncertainty on social preferences regarding environmental outcomes, in a climate change (CC) context. The environmental outcome chosen concerns the change in the level of biodiversity, expressed as the number of bird species in a particular locality. Under CC bird species' numbers could either decrease with no additional efforts or increase as a result of a policy change. This setting is ideal for studying the effect of environmental risks on preferences given that $\mathrm{CC}$ is associated with large uncertainties (Heal and Millner 2014). We use split-sample treatments to compare social preferences in a certain and an uncertain environmental scenario. Both treatments display the same expected outcomes in terms of anticipated species' losses and anticipated species' gains. The only difference is that one treatment shows each of these outcomes in a probabilistic way and the other one displays outcomes with certainty. Because people are known to often misunderstand probability (Patt and Dessai 2005; Lipkus 2007), our survey made an extensive effort to communicate it comprehensibly. We compare preferences between the certain and uncertain scenarios to shed more light on the role of uncertainty on respondents' preferences and WTP.

We find that people react differently to the prospect of achieving given environmental outcomes with certainty or uncertainty, even if expected outcomes are presented as equal. This confirms that individuals are not risk neutral when making environmental decisions under risk. Overall, our findings reinforce those of previous literature and show that uncertainty should be directly included in SP studies to provide more accurate and policy relevant results. Relative to previous literature, our research provides more robust insights into people's choices in the face of risk. Our study allows only for the effect of uncertainty, rather than also for the effect of changes in expected payoffs, to drive differences in preferences between the certain and uncertain scenarios. In addition, we provide further insight into what drives 
heterogeneous responses to uncertainty in a SP setting. In the specific environmental context of our analysis, we show that the effect of uncertainty depends, to some extent, on respondents' socio-demographic characteristics.

The rest of the paper is organized as follows. The next section (Sect. 2) provides an overview of previous attempts to study the effect of uncertainty within the SP valuation literature, highlighting the limitations of some of the earlier approaches. In addition, it also provides an overview of the existing studies examining the main drivers of risk attitudes. Section 3 describes the case study and the methodology employed for the analysis. Results are reported in Sect. 4, followed by a discussion and conclusions section that ends the paper.

\section{Literature Review}

\subsection{The Effect of Uncertainty in the Environmental Non-Market Valuation Literature}

The vast majority of SP research dealing with the non-market valuation of the environment does not consider uncertainty; however, an expanding number of studies in this area is designed in a risky context (see Torres et al. 2017 for a comprehensive review). These studies, mainly exploring people's preferences for environmental risk reductions, have found that individuals are willing to pay to decrease risks, which is often interpreted as an indicator of risk aversion, in line with the standard result of monetary lottery experiments in economics (Holt and Laury 2005; Charness et al. 2013). However, only a few SP studies have actually tested the effect of introducing uncertainty in the analysis of preferences, which requires comparing individuals' WTP for given environmental outcomes in a certain versus uncertain setting. Among these, Roberts et al. (2008) and Wielgus et al. (2009) explored preferences for environmental improvements by testing the effect of introducing information about the probability of policy success. In one split sample, they presented the environmental improvements without describing the probability of policy success and, hence, they have assumed outcome certainty. In one or more separate split samples, they displayed the same environmental improvements as uncertain (with a given probability of occurrence attached). Torres et al. (2017) have explored the effect on preferences of changing the information about the probability of CC impact occurrence. They compared WTP for given policy results to counteract $\mathrm{CC}$ induced negative environmental impacts across split samples-one assuming $\mathrm{CC}$ impact certainty and the other two assuming different degrees of CC impact uncertainty. Glenk and Colombo (2011) have first presented to respondents some choice cards without mentioning uncertainty before displaying another sequence of choice cards including one additional attribute reflecting the risk of failure of the policy. Based on these studies, introducing uncertainty in the decision context triggers significantly different (i.e. generally lower) preferences with respect to the case when individuals are exposed to certainty. However, it is not clear to what extent differences in preferences are driven by the presence or absence of uncertainty relative to the change (i.e. generally decrease) in expected outcomes triggered by the introduction of probabilistic information. In fact, following the approach adopted by the above studies, introducing uncertainty regarding the achievement of a given outcome can make the policy appear less worthwhile.

Only a few other SP studies, mostly contingent valuation exercises (Johansson 1989; Macmillan et al. 1996; Koundouri et al. 2014), have managed to isolate the effect of uncertainty on WTP for environmental goods. Using split samples, these authors compared respondents' WTP for environmental scenarios-presenting results as certain or uncertain (i.e. occurring with $50 \%$ probability). Additionally, in the certain and uncertain versions, they 
displayed equal expected outcomes, either in terms of environmental improvements resulting from policy efforts or in terms of environmental damages that would take place without policy intervention. Similarly, Isik (2006) used a contingent valuation study to analyse WTP for a given species' conservation target, presented as either certain or as a range of possible outcomes. Both certain and uncertain scenarios displayed the same average species target. In a CE exercise, Larue et al. (2017), explore preferences for different levels of probable reductions in water quality pollution. They describe expected water quality outcomes using different distributions, with changing mean and with (or without) dispersion-signalling the presence (or absence) of uncertainty.

In the presence of uncertainty, especially uncertainty regarding environmental processes, the results of scenarios both with and without policy to reduce environmental losses are subject to inherent and often uncontrollable uncertainty (Torres et al. 2017). However, none of the research reviewed in the paragraph above simultaneously presented both policy outcomes and outcomes resulting from no policy interventions as being subject to uncertainty. This omission may have distorted individuals' perceptions of the risk context. Omitting this information when presenting the scenarios could have had major repercussions in terms of individual behaviour and choices. In addition, these studies have often found highly heterogeneous responses to risk. In some results individuals were risk averse and tended to be willing to pay less for the scenario with uncertainty (Johansson 1989; Macmillan et al. 1996; Isik 2006; Larue et al. 2017), in others they were risk neutral and displayed no significantly different preferences for certain or uncertain scenarios (Koundouri et al. 2014). One of the reasons for these heterogeneous results may be that the effect of risk on social preferences can differ depending on a variety of factors that were not generally controlled for. These factors, reviewed in sub-Sect. 2.2, include the specific domain or scenario considered, the good, the direction of change over the good and the individuals' socio-demographic characteristics. By explicitly taking into account these aspects, our study aims to better understand the effect of uncertainty on preferences and WTP in an environmental domain and gather information on people's risk attitudes to better inform policy-makers and SP practitioners.

\subsection{Determinants of Risk Attitudes}

The economic literature provides ample evidence that individuals' attitudes to risk depend on a variety of factors. One of the most significant sources of observed heterogeneity of risk preferences is related to individuals' socio-demographic characteristics. Women are generally found to be more risk averse than men (Griffin et al. 1999; Eckel and Grossman 2008; Charness and Gneezy 2012). Older people tend to be more risk averse than younger ones (Nicholson et al. 2005; Mata et al. 2011). People with lower levels of education tend to be more risk averse (de Jonge et al. 2007). Individuals with lower wealth or with lower per-person/family income levels are generally more risk averse (Ding et al. 2010; Gong and Yang 2012). Previous experience (Barnett and Breakwell 2001; de Jonge et al. 2007), as well as emotional attachment to the good (Figner and Weber 2011) can both affect individuals' risk attitudes. Being out of the labour force (Dohmen et al. 2011) and being an employee, rather than self-employed (Hartog et al. 2002), are usually associated with more risk aversion. Married individuals are generally more risk averse (Guiso and Paiella 2004) and people with children in the household are sometimes more (Dohmen et al. 2011) and sometimes less risk averse (Ekelund et al. 2005).

Individuals also tend to display different risk attitudes depending on the direction and magnitude of change of the good affected by risk. People are generally more willing to take 
risks over lotteries implying possible losses rather than gains (Kahneman and Tversky 1979), but the perception of large, negative impacts can also trigger risk aversion. Individuals can also be risk averse over gambles displaying large changes in a given good, but less risk averse over gambles displaying small variations in the good (Nicholson and Snyder 2015).

Perhaps the most important finding for environmental economics, however, is the growing evidence that risk attitudes are domain-specific and vary depending on whether risks affect individuals in the health, financial, recreational, social, ethical or environmental domain (Weber et al. 2002; Riddel 2012). In this sense, given that most of the evidence available on risk attitudes relies on monetary lotteries, inferring risk attitudes over financial gambles to draw conclusions regarding risk attitudes in the environmental domain can be inappropriate (Blais and Weber 2006; Figner and Weber 2011; Bartczak et al. 2015, 2017). These findings have profound consequences for the non-market valuation of environmental goods because environmental scenarios are usually associated with different risks and uncertainties with respect to financial scenarios.

\section{Methodology and Data}

To investigate the effects of describing environmental changes as certain or uncertain and better understand respondents' reaction to risk with respect to gains or losses in an environmental domain, we designed and conducted a non-market valuation study in the context of climate change. Specifically, we looked at conservation policies in S'Albufera wetland in Mallorca (Spain), where climate change effects are likely to influence the number of 'specialist' and 'generalist' migratory bird species. We used split-sample treatments and described the levels of the environmental outcomes as either certain or uncertain, while holding the expected outcomes constant. Importantly, in our experiment all the outcomes (including the business as usual case, with no additional policy efforts) were either described as certain or uncertain, depending on the split sample. This provided us with an opportunity to separately study the effects of risk on preferences for uncertain gains and losses with respect to the status quo.

\subsection{Case Study}

S'Albufera wetland, located on the Mediterranean island of Mallorca (Spain), was used as a case study for the analysis of the effect of risk on individuals' preferences for environmental policies. This wetland, being the largest freshwater humid area of the island and supporting diverse and abundant flora and fauna species of international importance (Sato and Riddiford 2008), is ideal to investigate this research question. This is because the wetland, which is a natural park, is expected to be exposed to considerable risks induced by climate change (CC), with potentially negative impacts on bird species, the site's main natural asset. On the one hand, $\mathrm{CC}$ is anticipated to increase water salinization problems and lead to major alterations in the wetland's ecological conditions. These are expected to generate a decline in S'Albufera's 'specialist' bird species, which refer to those species that find their ideal habitat in this wetland. On the other hand, $\mathrm{CC}$ will also lead to alterations in migratory bird species' patterns, such that migratory birds, which visit the wetland for nesting and breeding, are predicted to arrive earlier to S'Albufera. Under such circumstances, migratory birds would not find optimal roosting conditions in the wetland and would be obliged to abandon the site or die. This would lead to a population decrease-especially in the number 
of S'Albufera's 'generalist' migratory bird species (species not typically or only occasionally seen in S'Albufera wetland). It is difficult, though, to predict the exact repercussions of climatic variations on bird species, particularly specialist ones, because CC impacts on the environment are largely unknown. ${ }^{2}$

In this framework, experts think that the implementation of additional management actions in the wetland may mitigate the loss of many bird species, which would be beneficial for wetland conservation and the recreationists who visit S'Albufera for its environmental quality. It is believed that the decline in the number of specialist bird species may be halted by maintaining current freshwater conditions at the site through the intensification of current water management efforts. Additionally, it is thought that the decline in the number of generalist migratory bird species would be counteracted by policies to maintain or increase optimal nesting and breeding conditions at the site. In any case, due to the uncertainty of CC impacts on the environment, the exact results of these policies, particularly those targeting specialist species, are also uncertain.

\subsection{Choice Experiment Design}

In order to examine how uncertainty drives individuals' (i.e. recreationists') preferences for alternative conservation policies, the DCE was considered the most suitable valuation method. DCEs obtain information about preferences for environmental policy outcomes by asking surveyed individuals to choose their preferred alternative among multiple sets of options, where each alternative is described by a different combination of environmental policy attributes. Additionally, DCEs can explore preferences in hypothetical and uncertain future scenarios, like in the case of CC, where information on people's preferences cannot be observed and is not available elsewhere. Indeed, the DCE method relies on the creation of controlled experiments, in which the effect on preferences of a specific treatment, the uncertainty of CC impacts in the present paper, can be isolated.

Two DCEs were designed to capture the effect of uncertainty on individuals' preferences for conservation policies. One DCE, used here as a control treatment and presented in Faccioli et al. (2015), illustrated a context in which CC impacts and the results of policies in S'Albufera were displayed as certain to respondents (certain treatment). In the second DCE, both CC impacts and, consequently, the results of policies appeared as uncertain (uncertain treatment). Respondents were randomly assigned to one of the treatments. This random assignment allowed us to study the effect of presenting the alternative scenarios of environmental change as uncertain versus certain and the results could be used for revealing some information about respondents' risk attitudes. This "between-subjects" approach, relying on the consideration of a certain and uncertain split samples, was chosen over a "within-subjects" approach, whereby each respondent would have been confronted with both the certain and uncertain treatments. The reason is that we wanted to avoid respondents' fatigue, issues of anchoring, endogeneity and reduced credibility of the questionnaire. ${ }^{3}$

2 CC impacts on specialist bird species will be more uncertain than those on generalist migratory bird species (Devictor et al. 2008). This is because specialist species, which are heavily dependent on the ecological condition in S'Albufera, will be more exposed to the variability and uncertainty of CC effects on the wetland than generalist species, which are less dependent on changes in the local ecological condition.

3 While we agree, as suggested by one reviewer, with the possible advantages of a within-subject approach, which would allow collecting individual-level information on preferences in a certain and uncertain setting, and therefore increasing the efficiency for statistical analysis, we also recognize that there are some limitations linked to such an approach. One issue is related to the credibility and realism of the scenario. Using a withinsubject approach, the same individual would first be asked to make choices in a certain (uncertain) setting and 
Table 1 Attribute descriptions and their levels in the certain and uncertain treatments

\begin{tabular}{|c|c|c|c|}
\hline & Description & Certain treatment & Uncertain treatment \\
\hline \multirow[t]{2}{*}{ Specialist bird species } & \multirow{2}{*}{$\begin{array}{l}\text { Change in the number of } \\
\text { species }^{\mathrm{a}}\end{array}$} & +5 & +4 or +6 , each with a $50 \%$ chance $(E V=+5)$ \\
\hline & & $0^{\mathrm{d}}$ & -4 or +4 , each with a $50 \%$ chance $\left(E V=0^{d}\right)$ \\
\hline \multirow{3}{*}{$\begin{array}{l}\text { Generalist migratory } \\
\text { bird species }\end{array}$} & \multirow{3}{*}{$\begin{array}{l}\text { Change in the number of } \\
\text { species }^{\mathrm{a}}\end{array}$} & +5 & +5 \\
\hline & & $0^{\mathrm{d}}$ & $0^{\mathrm{d}}$ \\
\hline & & $-10^{\mathrm{c}}$ & $-10^{\mathrm{c}}$ \\
\hline Waiting time & $\begin{array}{l}\text { Waiting time (in minutes) for } \\
\text { a seat in an observation } \\
\text { cabin }\end{array}$ & About 3 & About 3 \\
\hline \multirow[t]{3}{*}{ Rest-stop benches } & \multirow{3}{*}{$\begin{array}{l}\text { Number of benches } \\
\text { throughout the park }\end{array}$} & Triple & Triple \\
\hline & & Double & Double \\
\hline & & Equal $^{\mathrm{c}, \mathrm{d}}$ & Equal $^{\mathrm{c}, \mathrm{d}}$ \\
\hline Entrance fee & $\begin{array}{l}\text { Entrance fee per adult visitor } \\
\text { and trip (in euros) }\end{array}$ & $4,8,12,16,20,24$ & $4,8,12,16,20,24$ \\
\hline
\end{tabular}

${ }^{a}$ Changes with respect to the current number of bird species

${ }^{b}$ Number measured with respect to the current level of rest-stop benches

${ }^{\mathrm{c}}$ Level resulting from no additional policy effort over the next 10 years, being $€ 0$ for the Entrance fee attribute

${ }^{\mathrm{d}}$ Present level

In both DCEs, the alternative scenarios for S'Albufera's future in 10 years' time were described using the same five attributes reflecting management efforts that were perceived to be relevant for visitors. Two were environmental attributes - the change in the number of specialist bird species and generalist migratory bird species present in the wetland, compared to the present day. Three were non-environmental attributes - the waiting time for an observation cabin's seat, the number of benches throughout the park relative to current numbers, both being proxies for the amenities available in the wetland for visitors, and an entrance fee per adult visitor and day. For each non-monetary attribute, three levels were considered, which reflected the results of a no increase, moderate or high increase in management efforts with respect to current levels. ${ }^{4}$ Table 1 presents the attributes employed in the certain and uncertain DCE together with the attributes' levels.

The only difference between the two DCEs lies in the way the specialist bird species' attribute levels were presented. In one treatment, these were described as certain, whereas they were presented as uncertain in the other treatment. In this last treatment, uncertainty was described as being associated with limited knowledge of how $\mathrm{CC}$ events in the next

Footnote 3 continued

then asked to do the same in an uncertain (certain) setting, but it is questionable whether respondents would find both scenarios simultaneously credible. Also such an approach raises concerns about possible anchoring to whatever information was provided first, and about endogeneity in the sequence of respondents' choices. Individuals might take the information about certainty or uncertainty that was displayed first as a baseline and consider this also in subsequent scenarios, regardless of the new information provided by the researcher. Fatigue and mental effort are likely to be a problem too, when the certain and uncertain experiments are sequentially presented to each individual (Glenk and Colombo 2011).

4 The survey development included initial discussions and scoping interviews with park visitors (including foreigners), as well as meetings with the park manager, and, after the draft questionnaire was built, a pre-testing of the survey, followed by a pilot. 
10 years would affect the specialist bird species. ${ }^{5}$ More precisely, uncertainty around CC effects was described as being associated with either (1) the occurrence of a severe impact scenario, expected to take place with probability $\mathrm{p}_{1}$, or (2) the occurrence of a comparatively less severe impact scenario, which should take place with probability $\mathrm{p}_{2}$ (where $\mathrm{p}_{2}=1-$ $\mathrm{p}_{1}$ ). We set $\mathrm{p}_{1}$ and $\mathrm{p}_{2}$ at $50 \%$, which represents the maximum level of uncertainty. In the uncertain treatment, it was assumed that the change in the number of specialist bird species resulting from no increase, moderate or high increase in management efforts with respect to current levels would be uncertain. ${ }^{6}$ The study made considerable effort to communicate possible and expected outcomes and their probabilities to respondents (see Fig. 1).

For a given management effort, it was also assumed that the same change in the number of species, in expected value (EV) terms, would be achieved in both experiments. ${ }^{7}$ With this design, the comparison of respondents' behaviour under uncertainty and in the absence of uncertainty (i.e. in the control group) can provide useful information on risk attitudes. By definition, respondents can be classified as risk averse if they prefer a certain outcome to a lottery with the same expected outcome, risk neutral if they are indifferent between the two, or risk seeking if they prefer the lottery.

Additionally, in our exercise, we assumed that the range of possible changes in the number of specialist species resulting from a given management intervention shrinks with increasing conservation efforts. Therefore, without any policy intervention, the effect of $\mathrm{CC}$ on specialist bird species will vary from a loss of 16 specialist bird species to a loss of 4 species ( \pm 6 species around the EV of -10$)$. With medium policy efforts the range of outcomes varies from a possible loss of 4 to a possible increase of 4 ( \pm 4 bird species around the EV of 0 ). Finally, with high policy efforts, the number of species will increase, either by +4 or by $+6( \pm 1$ bird species around the EV of +5$)$. The presentation of a bigger variability of possible outcomes resulting from no policy efforts is justified by the fact that no adaptation under $\mathrm{CC}$ is likely to lead to more extreme situations than when adaptation efforts are implemented (Brooks 2003; IPCC 2014). ${ }^{8}$

In both DCEs, a D-efficient Bayesian experimental design was used to create alternatives combining the different attribute levels. The Bayesian D-efficient design was optimized for the mixed logit model. The priors for this design came from the estimated coefficients obtained from the analysis of the survey responses at the pilot stage, where an orthogonal design was used. The combinations resulting from the experimental design were then grouped into choice sets, with each choice set containing three alternatives. One fixed option, showing the "no policy' situation (or business as usual, BAU), specified what would occur in a time horizon of 10 years under current or no increased management efforts. In this alternative there was

\footnotetext{
5 Participants to focus group sessions and to initial scoping interviews organized with visitors found it credible to present the impacts of CC on the number of specialist bird species as uncertain and CC impacts on the number of generalist migratory bird species as certain.

6 In the uncertain version of the choice experiment, information about uncertainty was provided both through the attribute levels' description in the choice cards and through a framing statement: "The evolution of the number of specialist bird species in 10 years' time is uncertain. To make a comparison, it is like in a lottery, results are subject to a probability. In this sense, experts think that if park managers' efforts on current management practices are not strengthened, the decrease in the number of specialist bird species will occur with a probability equal to $50 \%$. Of course, the changes in the number of specialist bird species resulting from strengthening efforts will also be uncertain".

7 The EV is calculated as the sum of the probability-weighted outcomes that could result from a given event.

8 We are aware, as pointed out by one reviewer, that this might be a limitation of our study (as further discussed in the concluding section). We could have kept the spread of possible outcomes around the expected values constant for different levels of efforts, but our choice was driven by the willingness to increase the realism of the scenario presented to respondents.
} 


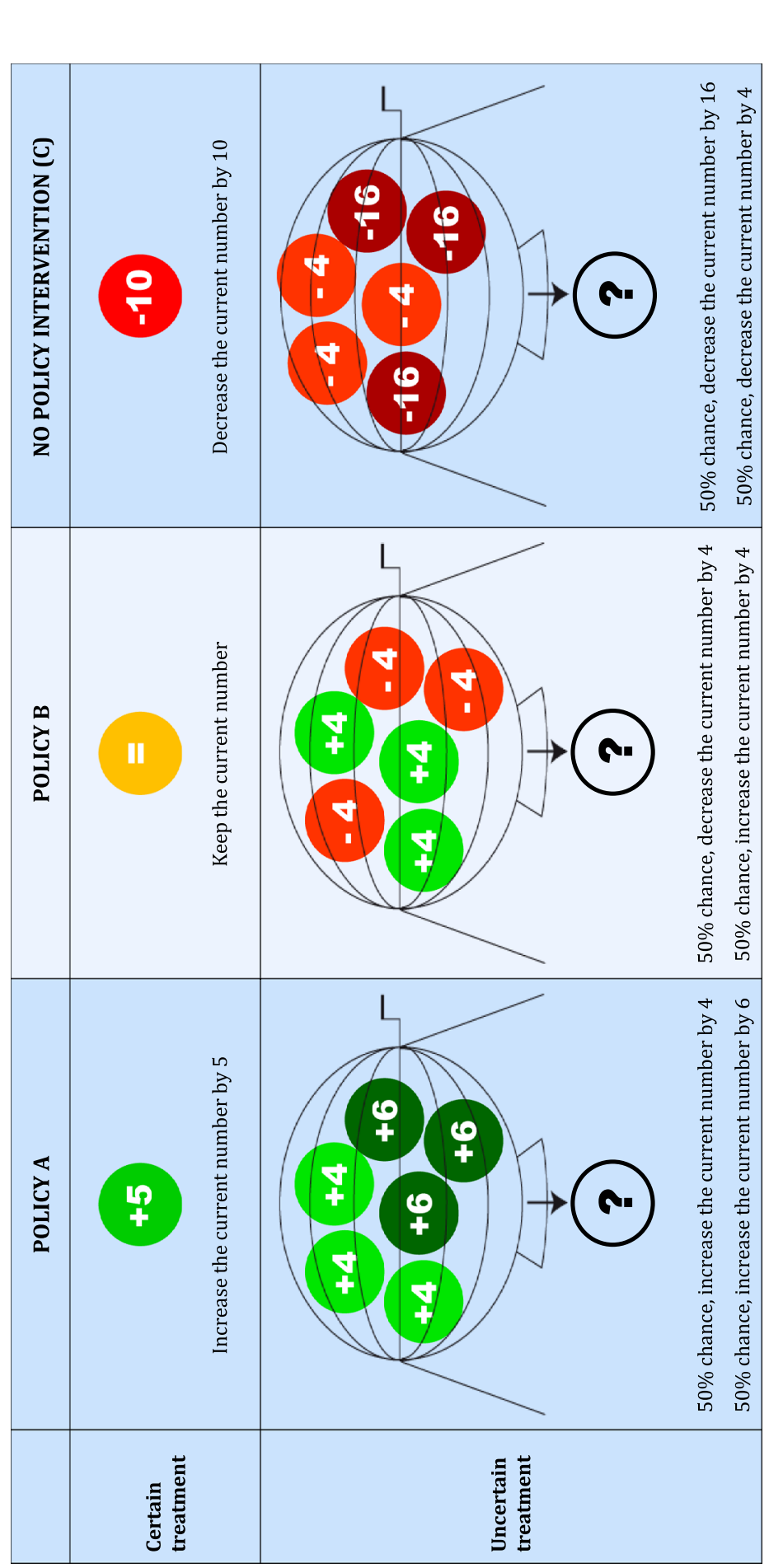

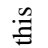

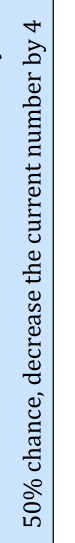

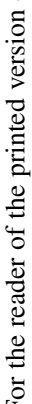

泀

氜

छ

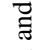

:

$\stackrel{0}{\Xi}$

.

马्ठ

పू.

ญัँ

:

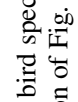

昰 윻

कू

4

है

余

\&

.

के

突.

을

눙요

눨

勇

考

就离 
a drop, on average, of 10 specialist and generalist migratory bird species, the current level of waiting time and rest-stop benches was displayed and there was no entrance fee. Then, in each choice card, two policy options were included, with improvements in at least one or more attributes with respect to the BAU situation and an entrance fee payment. An example choice card for each DCE is provided in Table 5 in the Appendix. Individuals were requested to select their preferred alternative in each of the six successive choice cards displayed to them.

\subsection{The Sample}

Both DCEs were implemented simultaneously through on-site, face-to-face interviews conducted with S'Albufera visitors between April and June 2013. Overall, 322 individuals were

Table 2 Visitation pattern of sampled respondents to S'Albufera ${ }^{\mathrm{a}}$

\begin{tabular}{|c|c|c|}
\hline & Certain treatment & Uncertain treatment \\
\hline \multicolumn{3}{|l|}{ Place of residence } \\
\hline Resident (in Mallorca) & $12.88 \%$ & $7.72 \%$ \\
\hline Non-resident & $87.12 \%$ & $92.28 \%$ \\
\hline \multicolumn{3}{|l|}{ Nationality } \\
\hline Spanish & $14.92 \%$ & $11.74 \%$ \\
\hline German & $41.02 \%$ & $42.62 \%$ \\
\hline British & $23.39 \%$ & $26.17 \%$ \\
\hline Other & $20.89 \%$ & $19.46 \%$ \\
\hline \multicolumn{3}{|l|}{ Main interest of the trip to Mallorca ${ }^{b}$} \\
\hline Nature enjoyment & $45.31 \%$ & $40.88 \%$ \\
\hline Relax & $30.08 \%$ & $36.50 \%$ \\
\hline Other ${ }^{\mathrm{c}}$ & $24.61 \%$ & $22.62 \%$ \\
\hline \multicolumn{3}{|l|}{ Main reason for visiting S'Albufera ${ }^{\mathrm{d}}$} \\
\hline Contemplation/enjoyment of nature & $42.03 \%$ & $46.64 \%$ \\
\hline Birdwatching & $30.51 \%$ & $29.87 \%$ \\
\hline Other & $27.46 \%$ & $23.49 \%$ \\
\hline \multicolumn{3}{|l|}{ Repeat visitation to S'Albufera } \\
\hline Repeat visitation (residents) & $63.16 \%$ & $69.57 \%$ \\
\hline Yearly visitation rate (median) & 1 & 2 \\
\hline Repeat visitation (non-residents - over the last 5 years) & $40.46 \%$ & $45.08 \%$ \\
\hline Visitation rate over the last 5 years (median) & 1 & 1 \\
\hline \multicolumn{3}{|l|}{ Travel parties $^{\mathrm{d}}$} \\
\hline Visiting the wetland with someone else & $87.46 \%$ & $82.88 \%$ \\
\hline Average number of accompanying people & 2.20 & 1.66 \\
\hline
\end{tabular}

${ }^{a}$ For the variables presented in the table, non-significant differences were detected at $1 \%$ level between the certain and uncertain treatments

${ }^{\mathrm{b}}$ Includes only non-residents

${ }^{c}$ Other includes: sun and beach, sport, fun and entertainment, family and friends, culture (art, history, gastronomy), holidays in a second home

${ }^{\mathrm{d}}$ Includes residents and non-residents 
Table 3 Socio-demographic profile of sampled respondents ${ }^{\mathrm{a}}$

\section{Certain treatment Uncertain treatment}

Age

Average respondent's age

Gender

Male

Female

\section{Education achieved}

Tertiary education

Other ${ }^{b}$

\section{Occupation}

Employee (part- and full-time)

Other ${ }^{\mathrm{c}}$

\section{Household members}

Average number of people in the household

No child(ren) below 16

Net monthly household income

Average net monthly household income
53

$53.56 \%$

$46.44 \%$

$50.51 \%$

$49.49 \%$

$56.27 \%$

$5.76 \%$

$37.97 \%$

$78.54 \%$

$83.59 \%$

54

$57.05 \%$

$42.95 \%$

$50.67 \%$

$49.33 \%$

$53.69 \%$

$8.05 \%$

$38.26 \%$

$3000-4000 € \quad 3000-4000 €$

${ }^{\mathrm{a}}$ For the variables presented in the table, non-significant differences at $1 \%$ level were detected between the certain and uncertain treatments

b Other includes: secondary education $(46.44 \%$ in the certain treatment and $46.64 \%$ in the uncertain one) and primary education

${ }^{\mathrm{c}}$ Other includes: own housekeeping, unemployed, (non-working) student and retired $(31.86 \%$ in the certain treatment and $33.89 \%$ in the uncertain treatment)

randomly sampled for the certain DCE and 318 for the uncertain one. The final dataset includes 295 individuals in the certain treatment and 298 in the uncertain treatment, providing a total of 3,558 observations ( six choice tasks per respondent). ${ }^{9}$

The main characteristics of the respondents confronted with both the certain and the uncertain treatments are summarized in Table 2. In both samples, individuals display the same profile based on selected variables. Most of the respondents were non-residents and mostly of German or British nationality. They were primarily motivated to travel to Mallorca for nature enjoyment and were interested in visiting S'Albufera to contemplate and enjoy nature or to carry out more specific activities, like birdwatching. They show repeat visitation rates to the park and generally travel in small groups.

Concerning the socio-demographic profile of respondents, summarized in Table 3, S'Albufera visitors tend to be middle aged, with slightly more males than females in the sample. Their education level is generally high (typically a university or post-graduate degree) and more than half of respondents are employees. On average, the size of the respondents' households generally consists of two or three adults living together and no children below 16. Visitors' monthly average net household income is between 3000 and 4000 euros.

\footnotetext{
9 Invalid and protest responses were removed from the data set. Surveys were considered invalid when missing responses were detected in the choice of the alternatives or in other variables relevant for the modelling. Protest respondents were identified as those choosing the BAU option for the following reasons: (i) "I don't perceive any problem to justify extra efforts on current practices", (ii) "I consider I am already paying for these services", (iii) "Others should pay" and iv) "I don't trust the local authorities."
} 
Through the statistical analysis of respondents' choices, information could be obtained concerning individuals' preferences regarding the implementation of a conservation policy in the wetland. More precisely, and as described in the following section, we are interested in comparing the results obtained in the certain treatment with those in the uncertain treatment.

\subsection{Econometric Framework}

According to the random utility maximization (RUM) theory (McFadden 1974), which represents the usual framework for modelling choice data, the utility respondent $n$ obtains from a specific scenario $j$ of the conservation program relies on a deterministic term $\beta_{n}^{\prime} X_{n j}$, which is a function of the $k$ attributes of this scenario including cost, and a random term $\varepsilon_{n j}$ :

$$
U_{n j}=\beta_{n}^{\prime} X_{n j}+\varepsilon_{n j}
$$

where $\varepsilon_{n j}$ follows a Gumbel distribution, $X_{n j}$ is the vector of $k$ attributes describing alternative $j$ faced by respondent $n$ and $\beta_{n}^{\prime}$ is the vector of $k$ preference parameters. The results section of this paper is based on the mixed logit model (MXL; McFadden and Train 2000; Train 2009), which is the state-of-practice in the econometric analysis of discrete choice data. ${ }^{10}$ The model accounts for preference or WTP heterogeneity following a particular parametric distribution-in our case a normal distribution with mean $b$ and standard deviation $\sigma$, excepted for the entrance fee (cost)/scale parameter, which was assumed to be log-normally distributed to restrict the sign of this coefficient to be the same over all respondents.

To facilitate interpretation of the results we also specify the model in WTP-space (Train and Weeks 2005; Scarpa et al. 2008):

$$
U_{n j}=\beta_{n}^{\prime m}\left(X_{n j}^{m}+\beta_{n}^{\prime-m} X_{n j}^{-m}\right)+\varepsilon_{n j},
$$

where $X_{n j}^{m}$ is the monetary attribute, $X_{n j}^{-m}$ are all other attributes, $\beta_{n}^{\prime m}$ is the parameter for the monetary attribute and $\beta_{n}^{\prime-m}$ is the vector of parameters for the non-monetary attributes. Multiplying all attributes by the parameter of the monetary attribute allows for the vector of preference parameters $\beta_{n}^{\prime-m}$ to be interpreted as a vector of implicit prices (marginal WTPs).

Our models account for possible scale differences between subsamples (treatments). Letting $T_{n}$ represent a dummy variable associated with the uncertain treatment (relative to the certain treatment), we can define the model as:

$$
U_{n j}=\alpha_{n} \beta_{n}^{\prime} X_{n j}+\varepsilon_{n j},
$$

where $\alpha_{n}=\exp \left(\theta T_{n}\right)$ accounts for the treatment-specific scale (the variance of the error term in relation to the magnitude of all the coefficients). The estimated parameter $\theta$ describes whether the scale is higher or lower in the uncertain treatment with respect to the reference (certain) treatment. A positive (negative) value of $\theta$ would mean that overall the choices made in the uncertain treatment appear to be less (more) random from the modeller's perspective with respect to choices in the control group. Note that without controlling for the possible scale differences the observed differences in preference or WTP parameters between treatments could be driven by variations in the choices observed in one of the treatments. This situation could easily occur by introducing (or not) uncertainty into the survey script (Czajkowski et al. 2014, 2016).

10 In the Appendix and the supplementary materials we also include the results of the analysis based on the $\mu$-random regret model (van Cranenburgh et al. 2015) and the logit-mixed logit model (Train 2016). 
In addition, for the purposes of the study, our model also allows treatment-specific effects to be estimated for the specialist bird species attribute. Taking the above into account, the utility function becomes:

$$
\begin{aligned}
U_{n j}= & \alpha_{n}\left(\beta_{0, n} \cdot A S C_{n j}+\beta_{1.1, n} \cdot X_{S P E C-10, n j} \cdot\left(1-T_{n}\right)+\beta_{1.2, n} \cdot X_{S P E C-10, n j} \cdot T_{n}+\beta_{2.1, n} \cdot X_{S P E C+5, n j} \cdot\left(1-T_{n}\right)\right. \\
& +\beta_{2.2, n} \cdot X_{S P E C+5, n j} \cdot T_{n}+\beta_{3, n} \cdot X_{G E N-10, n j}+\beta_{4, n} \cdot X_{G E N+5, n j}+\beta_{5, n} \cdot X_{T I M E_{7}, n j}+\beta_{6, n} \cdot X_{T I M E_{3}, n j} \\
& +\beta_{7, n} \cdot X_{B E N C H E S_{\text {double }, n j}}+\beta_{8, n} \cdot X_{\left.B E N C H E S_{\text {triple }, n j}+\beta_{9, n} \cdot X_{C O S T, n j}\right)+\varepsilon_{n j},}
\end{aligned}
$$

$\mathrm{ASC}_{\mathrm{nj}}$ is the Alternative Specific Constant for the BAU Alternative. $X_{S P E C-10, n j}$ takes the value 1 when the specialist bird species' attribute decreases by an expected value of 10 with respect to current levels, while $X_{S P E C+5, n j}$ takes the value 1 when the specialist bird species' attribute is increased with respect to current levels by an expected value of +5 . $X_{G E N-10, n j}$ is the dummy variable for a decrease by 10 in the number of generalist bird species with respect to current levels and $X_{G E N+5, n j}$ takes the value 1 when the generalist bird species' attribute is increased by 5 with respect to current levels. $X_{T I M E_{7}, n j}$ is a dummy variable for a reduction in waiting time to 7 minutes (from the current level of 15) and $X_{T I M E_{3}, n j}$ is a dummy variable for a reduction in waiting time to 3 minutes (from the current level of 15). $X_{B E N C H E S_{\text {double }, n j}}$ takes the value 1 when the number of benches is doubled with respect to current levels, while $X_{B E N C H E S_{\text {triple }}, n j}$ takes the value 1 when the number of benches is tripled with respect to current levels. Finally, $X_{C O S T, n j}$ is the value of the entrance fee.

If uncertainty plays a role in individuals' preferences for alternative policy options for the conservation of S'Albufera wetland, and hence people are not risk neutral, then presenting changes in the numbers of the specialist bird species as certain or uncertain (i.e., our treatments) is expected to affect the weight of this attribute in respondents' utility function (i.e., the mean of the estimated distribution). In addition, testing if parameters obtained under certainty are higher (respectively lower) than their counterparts obtained under uncertainty reveals that respondents confronted with the certain treatment derive an on average higher (respectively lower) increase in utility or WTP from a given change in the number of specialist bird species than respondents confronted with the same expected environmental change under uncertainty.

\section{Results}

Table 4 presents the results ${ }^{11}$ of the MXL models in preference and WTP-space (in euros). The coefficients represent means and standard deviations of the distributions of our respondents' preferences or marginal WTP. They imply that respondents, on average, disapprove of the business-as-usual scenario in favour of some new conservation policy (as indicated by the negative coefficient of the mean WTP associated with the alternative specific constant for the business-as-usual option). The valuations of individual components of such a new policy vary. A decrease in the population of specialist birds is worth - 5.62 EUR in the certain treatment and - 6.92 EUR in the uncertain treatment, while a decrease in the number of generalist migratory bird species is valued at -4.39 EUR. The mean WTP for increasing the number of

\footnotetext{
11 The software codes for estimating the MXL model were developed in Matlab and are available at http://gi thub.com/czaj/DCE under Creative Commons BY 4.0 license. The codes for estimating the models presented in this paper, as well as the supplementary material, are available from http://czaj.org/research/supplementar y-materials. For more information on the data, the interested reader should contact the corresponding author.
} 
specialist bird species is 0.42 EUR in the certain treatment and 3.52 EUR in the uncertain treatment. The mean WTP for increasing the number of generalist bird species is not significantly different from 0 . At the same time, respondents have positive mean WTP for reducing the average waiting time from 15 to 7 minutes, but are not necessarily so keen on a further reduction of time (to 3 minutes), as indicated by lower mean WTP values for this attribute level. They also have positive WTP for doubling the number of benches, but not for tripling the number of benches, which is actually associated with negative mean WTP, suggesting a u-shaped relationship. The coefficients of the negative cost attribute presented in Table 4 are significant and of expected sign, but do not have an absolute level interpretation in the WTP-space model. ${ }^{12}$ Finally, we note that the parameters of the explanatory variable of scale associated with the uncertain treatment are negative and significant. This implies that, relative to the certain treatment, the uncertain treatment (explicitly acknowledging the uncertainty around the expected change in specialist species) displays a lower scale and, hence, higher variation of choices (higher error term variance). This means that (from the modeller's perspective) respondents in the uncertain treatment tend to make choices that are more random than in the certain treatment. $^{13}$

Presenting outcomes as certain or uncertain significantly changes respondents' preferences and WTP. A likelihood ratio (LR) test shows that the model in preference-space presented in Table 4 is a significantly better fit than the model in which the parameters for the specialist bird species are not treatment-specific (model 1 in Table 6 in the Appendix). More precisely, we find that the probability of making an error when rejecting the null hypothesis that the parameters for the changes in the specialist bird species are equal between the certain and uncertain treatments, is less than 0.05 . This is true also when separately focusing either on the parameter for the increase in the number of specialist species or on the parameter for the decrease in specialist species. We provide evidence on this by comparing model 1 with models 2 and 3 in Table 6 in the Appendix. ${ }^{14}$ As a result, with very little probability of error we can reject the null hypothesis that the treatments did not influence respondents' preferences (WTP) for the 'uncertain' attribute. This indicates that presenting the changes in specialist bird species' numbers during the next 10 years as certain or uncertain significantly changes respondents' observed preferences and WTP, even when the scale differences between treatments are controlled for.

Looking at the differences in respondents' preferences and WTP arising from presenting outcomes as uncertain versus certain, two things stand out. First, the uncertain treatment results in stronger preferences/higher WTP (in absolute terms) than the certain treatment. In

\footnotetext{
12 Note that the coefficients reported correspond to the underlying normal distribution that is used to generate the log-normally distributed parameters, $\beta_{n}^{m}$. By assumption, the sign of the parameters of the negative cost/scale is positive.

13 Note that in the WTP-space specification the coefficient for the scale $(\theta)$ is confounded with the coefficient of the monetary attribute $\left(\beta_{n}^{m}\right)$. Consequently, one cannot be sure if the observed result reflects treatmentspecific differences in the scale or in the marginal utility of money (or possibly both). We therefore use the results of the preference-space models as more informative about the scale differences between the treatments.

14 Given the nested nature of the models compared, the use of the LR test is appropriate. $<0.01$

LR test comparing mixed logit in preference-space (Table 4) vs Model 1 (Table 6 in the Appendix): $p$

LR test comparing Model 1 vs Model 2 (Table 6 in the Appendix): $p<0.01$

LR test comparing Model 1 vs Model 3 (Table 6 in the Appendix): $p<0.02$

We additionally replicated the same LR tests by considering the models in WTP-space and found that it was possible to reject all the above null hypotheses with very low probabilities of error $(p<0.001)$. The models in WTP-space used for these tests are available in the supplementary materials.
} 
Table 4 Mixed logit model results representing preferences and marginal WTP (EUR) for changes in specific conservation attributes

\begin{tabular}{|c|c|c|c|c|}
\hline & \multicolumn{2}{|c|}{ Preference-space } & \multicolumn{2}{|l|}{ WTP-space } \\
\hline & $\begin{array}{l}\text { Mean } \\
\text { (St. error) }\end{array}$ & $\begin{array}{l}\text { St. deviation } \\
\text { (St. error) }\end{array}$ & $\begin{array}{l}\text { Mean } \\
\text { (St. error) }\end{array}$ & $\begin{array}{l}\text { St. deviation } \\
\text { (St. error) }\end{array}$ \\
\hline Business as usual-alternative specific constant & $\begin{array}{l}-3.653^{* * *} \\
(0.453)\end{array}$ & $\begin{array}{l}3.456 * * * \\
(0.597)\end{array}$ & $\begin{array}{l}-4.515^{* * *} \\
(0.054)\end{array}$ & $\begin{array}{l}6.387 * * * \\
(0.029)\end{array}$ \\
\hline Specialist bird species: $0 \rightarrow-10$ (certain) & $\begin{array}{l}-3.153 * * * \\
(0.406)\end{array}$ & $\begin{array}{l}1.457 * * * \\
(0.430)\end{array}$ & $\begin{array}{l}-5.622 * * * \\
(0.041)\end{array}$ & $\begin{array}{l}3.236 * * * \\
(0.034)\end{array}$ \\
\hline Specialist bird species: $0 \rightarrow-10$ (uncertain) & $\begin{array}{l}-3.825^{* * *} \\
(0.574)\end{array}$ & $\begin{array}{l}3.053 * * * \\
(0.590)\end{array}$ & $\begin{array}{l}-6.917 * * * \\
(0.062)\end{array}$ & $\begin{array}{l}7.110 * * * \\
(0.028)\end{array}$ \\
\hline Specialist bird species: $0 \rightarrow+5$ (certain) & $\begin{array}{l}0.644 * * \\
(0.276)\end{array}$ & $\begin{array}{l}0.063 \\
(3.005)\end{array}$ & $\begin{array}{l}0.415 * * * \\
(0.050)\end{array}$ & $\begin{array}{l}1.829 * * * \\
(0.095)\end{array}$ \\
\hline Specialist bird species: $0 \rightarrow+5$ (uncertain) & $\begin{array}{l}1.495 * * * \\
(0.376)\end{array}$ & $\begin{array}{l}1.867 * * * \\
(0.594)\end{array}$ & $\begin{array}{l}3.518 * * * \\
(0.076)\end{array}$ & $\begin{array}{l}4.536 * * * \\
(0.045)\end{array}$ \\
\hline Generalist migratory bird species: $0 \rightarrow-10$ & $\begin{array}{l}-2.453^{* * *} \\
(0.335)\end{array}$ & $\begin{array}{l}1.468 * * * \\
(0.306)\end{array}$ & $\begin{array}{l}-4.386^{* * * *} \\
(0.044)\end{array}$ & $\begin{array}{l}3.742 * * * \\
(0.017)\end{array}$ \\
\hline Generalist migratory bird species: $0 \rightarrow+5$ & $\begin{array}{l}0.240 \\
(0.190)\end{array}$ & $\begin{array}{l}0.293 \\
(1.386)\end{array}$ & $\begin{array}{l}0.045 \\
(0.039)\end{array}$ & $\begin{array}{l}0.327 * * * \\
(0.020)\end{array}$ \\
\hline Waiting time reduced: $15 \rightarrow 7$ & $\begin{array}{l}0.617 * * * \\
(0.202)\end{array}$ & $\begin{array}{l}0.303 \\
(0.714)\end{array}$ & $\begin{array}{l}2.246 * * * \\
(0.037)\end{array}$ & $\begin{array}{l}1.241 * * * \\
(0.024)\end{array}$ \\
\hline Waiting time reduced: $15 \rightarrow 3$ & $\begin{array}{l}0.376 * * \\
(0.174)\end{array}$ & $\begin{array}{l}0.784 * \\
(0.426)\end{array}$ & $\begin{array}{l}0.616 * * * \\
(0.040)\end{array}$ & $\begin{array}{l}3.440 * * * \\
(0.023)\end{array}$ \\
\hline Number of rest-stop benches: doubled & $\begin{array}{l}0.685 * * * \\
(0.180)\end{array}$ & $\begin{array}{l}0.666 \\
(0.459)\end{array}$ & $\begin{array}{l}0.373 * * * \\
(0.033)\end{array}$ & $\begin{array}{l}1.969 * * * \\
(0.019)\end{array}$ \\
\hline Number of rest-stop benches: tripled & $\begin{array}{l}-0.299 \\
(0.224)\end{array}$ & $\begin{array}{l}1.841 * * * \\
(0.344)\end{array}$ & $\begin{array}{l}-1.538^{* * * *} \\
(0.030)\end{array}$ & $\begin{array}{l}4.940 * * * \\
(0.020)\end{array}$ \\
\hline -Cost & $\begin{array}{l}1.760 * * * \\
(0.110)\end{array}$ & $\begin{array}{l}0.804 * * * \\
(0.052)\end{array}$ & $\begin{array}{l}4.093 * * * \\
(0.627)\end{array}$ & $\begin{array}{l}2.620 * * * \\
(0.451)\end{array}$ \\
\hline \multicolumn{5}{|l|}{ Covariates of scale } \\
\hline Uncertain treatment & $\begin{array}{l}-0.440^{* * * *} \\
(0.021)\end{array}$ & & $\begin{array}{l}-0.566 \\
(0.415)\end{array}$ & \\
\hline \multicolumn{5}{|l|}{ Model diagnostics } \\
\hline LL at convergence & \multicolumn{2}{|c|}{-2146.41} & \multicolumn{2}{|c|}{-2240.26} \\
\hline LL at constant(s) only & \multicolumn{2}{|c|}{-3907.27} & \multicolumn{2}{|c|}{-3907.27} \\
\hline McFadden's pseudo- $\mathrm{R}^{2}$ & \multicolumn{2}{|l|}{0.451} & \multicolumn{2}{|c|}{0.427} \\
\hline Ben-Akiva-Lerman's pseudo- $\mathrm{R}^{2}$ & \multicolumn{2}{|l|}{0.572} & \multicolumn{2}{|c|}{0.560} \\
\hline $\mathrm{AIC} / n$ & \multicolumn{2}{|l|}{1.221} & \multicolumn{2}{|c|}{1.273} \\
\hline $\mathrm{BIC} / n$ & \multicolumn{2}{|l|}{1.264} & \multicolumn{2}{|c|}{1.317} \\
\hline$n$ (observations) & \multicolumn{2}{|l|}{3558} & \multicolumn{2}{|c|}{3558} \\
\hline$r$ (respondents) & \multicolumn{2}{|l|}{593} & \multicolumn{2}{|c|}{593} \\
\hline$k$ (parameters) & \multicolumn{2}{|l|}{25} & \multicolumn{2}{|c|}{25} \\
\hline
\end{tabular}

Standard errors are provided in parentheses. All utility function parameters are modelled as random and normally distributed except for the cost parameter, which is assumed to follow a log-normal distribution (the estimates of the underlying normal distribution are provided). The models were estimated using the simulated maximum likelihood method with 10,000 Sobol draws with a random linear scramble and a random digital shift (Czajkowski and Budziński 2017) $* * *, * *$ and $*$ indicate 1,5 and $10 \%$ significance levels, respectively 
other words, when respondents are informed about the uncertainty around expected outcomes, losses in the number of specialist bird species seem more severe to them, and increases in the number of specialist bird species appear more beneficial. Second, despite both the certain and uncertain treatments displaying on average the same expected environmental changes, reporting a range of possible losses or improvements in the specialist bird species (rather than just the expected value) results in substantially larger heterogeneity in individual's preferences and WTP, as implied by considerably larger estimates of standard deviations of the parametric distributions. We discuss these results in more detail in the discussion section.

Because our results imply considerable unobserved heterogeneity in preferences and WTP, as indicated by the relatively large estimates of standard deviations, following the recommendation of one of our reviewers, in Table 7 in the Appendix we explore this heterogeneity using the $\mu$-random regret minimization (RRM) model ( $\mu$ RRM; van Cranenburgh et al. 2015). ${ }^{15}$ We find that, in the case of our data, the $\mu$ RRM exhibits a behaviour which is relatively close to linear-additive random utility maximization. This is because the model estimates a high value for the coefficient $\mu$, which signals a relatively small profundity of regret and suggests no random regret minimization behaviour. As a result, the $\mu \mathrm{RRM}$ does not offer significant improvements over the traditional multinomial logit model based on random utility maximization and it is outperformed by the MXL model, in terms of the model fit. Additionally, to investigate the robustness of our results to imperfect assumptions with respect to the parametric distributions of preferences or WTP, Table 8 in the Appendix presents the results of the semi-parametric logit-mixed logit (LMXL) model (Train 2016). ${ }^{16}$ While we find that this latter can lead to gains in model fit, the results of our study regarding the effects of explicitly stated uncertainty on preferences for decreases and increases in the 'uncertain' attribute, remain qualitatively unchanged.

Finally, in order to deepen our understanding of how risk attitudes are linked with respondents' socio-demographic characteristics, we estimated an additional MXL model, in which deviations from the risk neutral behaviour are interacted with respondent's sociodemographic characteristics. In this model, we assumed that respondents in the certain and uncertain treatment have equal tastes (and hence are neutral to risk), while simultaneously analysing the preferences of those exposed to the uncertain treatment to see whether and how their behaviour deviates from the assumption of preference equality across treatments. We explain the behaviour of this latter group of respondents using interactions with selected socio-demographic variables. The results are presented in Table 9 in the Appendix. We find that, while the uncertain treatment generally reduces the mean WTP associated with reductions in the population of the specialist bird species, this effect is stronger for respondents who are male, older (although with diminishing effect), have children below 16, live in households with fewer people, have lower income (with diminishing effect), have tertiary education

15 RRM models are alternative choice modelling frameworks to the more widely used RUM approach and they postulate that, when choosing, decision makers try to minimize regret, which is experienced when one or more non-chosen alternatives outperform the chosen one, in terms of one or more attributes. The $\mu$-RRM is a more flexible generalization of the classical RRM model (see van Cranenburgh et al. 2015 for more details).

16 LMXL models represent generalizations of the MXL model in that they allow specifying the distribution of random parameters with a high degree of flexibility. Beyond the consideration of normal, log-normal or triangular distributions, which are notoriously subject to some limitations, the LMXL allows the researcher to specify more flexible distributions by considering polynomials, splines, steps, and other functions that have been developed for general approximation. Each parameter value has a probability associated to belong to the specified distribution and such probability is estimated through a logit function (see Train 2016 for more details on the model). 
and are not self-employed. At the same time, the uncertain treatment increases WTP for the increase in the population of these birds, and this effect is stronger for respondents who are male, older, do not have children or have many children, live in smaller households, have lower income, do not have tertiary education, are employees or are not self-employed. These results provide an insight into which respondents are more likely to be sensitive to the effect of risk.

\section{Discussion and Conclusions}

The aim of this study was to explore the impact of uncertainty on individuals' preferences and WTP for environmental policies. We expected that making the uncertainty about environmental outcomes explicit would influence people's stated preferences. To test this, we designed and conducted a DCE, in which, in a split-sample setting, the changes resulting from different environmental policy efforts (i.e. both increased efforts and no extra efforts) were described as certain or uncertain, while having the same expected outcomes across treatments. As detailed later in this section, adopting this approach allowed us to gain a better understanding, relative to previous SP literature, of the effect of uncertainty on preferences and of the attitudes of individuals to risk in an environmental setting. The empirical study focused on recreationists' preferences for policies to avoid a CC induced decrease in the number of specialist bird species in S'Albufera wetland in Mallorca (Spain).

We find that preferences and WTP for environmental outcomes are significantly different if SP valuation scenarios are presented as uncertain rather than certain, despite in both cases the same expected outcomes are considered. Hence, our findings confirm that risk plays an important role in individuals' choices and people are not risk neutral (Holt and Laury 2005; Charness et al. 2013). Our results show that respondents perceive more disutility from an uncertain decrease in the specialist bird species relative to a certain decrease. On the other hand, when respondents consider increases in the number of specialist bird species with respect to current levels, the uncertain treatment results in significantly higher estimates than the certain treatment. In other words, despite both the certain and uncertain treatments displaying on average the same expected environmental change, reporting a range of possible variations in the specialist bird species (rather than just the expected value) results in larger changes in utility and greater variations in WTP. These results are robust to scale differences, various model specifications (preference- and WTP-space MXL models), different approaches to modelling preference heterogeneity (LMXL models) and non RUM-based approaches to modelling choices ( $\mu$ RRM).

Lower utilities and WTP associated with uncertain losses compared to certain losses with the same expected value would suggest that respondents are risk averse. On the other hand, higher utilities and WTP for uncertain gains, relative to the certain situation, may imply risk seeking behaviour. Asymmetry with respect to risk attitudes over gains and losses is often found in behavioural studies (e.g., Kahneman and Tversky 1979). However, our results are not fully consistent with prospect theory: our study would suggest that respondents are risk averse for environmental losses and risk seeking with respect to environmental improvements, while prospect theory shows that people are generally risk seeking relative to monetary losses and risk averse over monetary gains. This result could be an indication of domain-specific risk attitudes and suggest that what is observed in financial lottery experiments is not necessarily 
applicable to environmental decisions (Blais and Weber 2006; Figner and Weber 2011). ${ }^{17}$ However, we acknowledge the limitations of our study and note that other explanations are possible. First, despite presenting the certain and uncertain outcomes as equal in terms of expected values, respondents could have perceived the proposed policy results differently. They could have anchored to the best or the worst environmental outcomes (e.g., considering some changes as irreversible), or engage in some other form of probability weighting. Next, note that the degree of variation associated with losses with respect to gains is not equal, with more spread outcomes in the case of losses, than gains. Our conclusions regarding respondents being risk averse for losses and risk seeking for gains is based on the assumption that individuals use the current level ( 0 change) as a reference. However, it is also possible that some of the respondents use other attribute levels as a reference (e.g., the reduction associated with the business-as-usual scenario; Bateman et al. 1997, 2005). Additionally, it must be noted that individuals may have difficulty understanding probability or making consistent decisions in this context (e.g., Patt and Dessai 2005; Lipkus 2007). Finally, we note that our results are based on a single data set. Although we designed and conducted the study to provide useful insight into social preferences for conservation policies under uncertainty, it remains to be seen if future studies confirm that our results can be generalized to other conservation policies, environmental goods, and other respondent groups (non-recreationists).

Irrespective of respondents' general risk aversion or risk seeking attitudes, our results highlight the non-neutrality of people to risk and the significance of accounting for the fact that conservation efforts are often implemented in a context of uncertainty. Most empirical works do not explicitly include uncertainty and present outcomes as expected results (certain). These studies therefore assume that people are indifferent to risk. Despite an increasing number of SP researchers finding that incorporating risk in the valuation exercise has an impact on preferences (cf. Roberts et al. 2008; Wielgus et al. 2009; Glenk and Colombo 2011 and others), the understanding of people's environmental preferences in a risky context is still limited. Some of the previous attempts have explored the effect of uncertainty, while allowing the possible expected outcomes to vary. However, because of confounding variations in the level of uncertainty with changes in expected outcomes, these studies have not been able to reach clear conclusions regarding the role of uncertainty and people's attitudes to risk. Rather, previous research has tended to assume that positive preferences for higher expected outcomes (which, in these studies, are linked to lower levels of risk) reflect risk aversion, which is the standard result in economics. To gain a genuine understanding of the role of risk on preferences, we have compared choices in certain and uncertain scenarios, both displaying the same expected outcomes. Only a scant SP literature, mostly contingent valuation studies, have previously followed a similar approach (Johansson 1989; Macmillan et al. 1996; Isik 2006; Koundouri et al. 2014). However, compared to these studies, our research provides a better

\footnotetext{
17 Whereas most economists tend to believe that people's reactions to risk are inherent and stable across outcome domains, there is growing evidence that this may not be true. For example, earlier studies found higher levels of risk aversion over life duration gambles than financial gambles and higher willingness to take health and safety risks rather than social risks. Regarding people's reactions to risks over the financial and environmental domain, some evidence exists that subjects tend to be more in favour of mitigating environmental gambles than financial gambles with the same odds and equivalent outcomes (Riddel 2012). It has been speculated that this divergence in perceived risks could be due to the fact that individuals may be less familiar with environmental risks than financial risks, leading them to be overly cautious (more risk averse) about (potentially irreversible) environmental degradation and overly optimistic (less risk averse) about the likelihood of designing a successful environmental improvement program. Alternatively, it could be that subjects are using more caution (risk aversion) because the public-good nature of many types of environmental damage is not limited to personal losses (as in the case of financial outcomes), but affects society as a whole. Certainly, more research on the source of domain specificity for environmental risks is warranted.
} 
and more realistic understanding of the role of uncertainty and risk attitudes on preferences. Unlike previous attempts, our CE study simultaneously presents the situation with and without policy as being subject to uncertainty. In addition, we give explicit attention to the variability of risk attitudes, for instance, by looking at differences in individuals' characteristics. The findings of our research highlight the importance of considering individual-specific risk attitudes in an environmental context.

We observe several socio-demographic characteristics that play a role in respondents' sensitivity to risk (help explain deviations from risk neutral behaviour). Some of these results can be related to more general findings in the economics literature, e.g. where higher age and lower income are usually recognized to trigger more risk aversion (Mata et al. 2011; Gong and Yang 2012). However, some others, e.g. males being more sensitive to uncertain losses than women, are not generally found in monetary lottery experiments (Eckel and Grossman 2008). This highlights the specificity of individuals' perception of and attitude to risk in an environmental domain. As a result, assuming a priori, as traditionally done in economics, that individuals are risk averse and prefer a certain to an uncertain situation, despite both providing the same expected results, could lead to erroneous decisions in uncertain contexts. An interesting venue for future research might be to improve the understanding of the psychological aspects underlying risk perceptions, as these factors are also expected to be important in determining individuals' risk attitude (Fooken and Schaffner 2016).

Overall, a better understanding of the way people behave in uncertain situations and different contexts can be helpful to guide policy-makers. Given that environmental policies are implemented in an increasingly uncertain context, knowledge about the influence of uncertainty on people's preferences and WTP can provide more accurate measures of public support for environmental interventions. Failing to take uncertainty and risk attitudes into account might lead to biased estimates of individuals' preferences and willingness to pay to conserve the environment and therefore to erroneous decision-making regarding environmental policy options. ${ }^{18}$

In conclusion, the fact that respondents are not neutral to the uncertainty regarding the results of conservation policies indicates the importance of explicitly describing the outcomes of environmental policies as risky in SP studies to obtain more accurate and policy relevant results. Presenting the environmental policy outcomes in terms of expected results, which can be achieved with certainty, can lead to the estimation of welfare measures that are inconsistent with the true preferences of the public for inherently uncertain environmental policy options. Similarly, assuming that respondents are generally risk neutral (or risk averse, as often done) may not reflect their true attitudes towards risk in an environmental domain.

Acknowledgements The data collection for this research work was conducted under the Training Program for University Professors of the Spanish Ministry of Education, Culture and Sport (AP2010-3810) and has received financial support from the Government of the Balearic Islands through the Special Action Program (AAEE025/2012) and the CICYT Program of the Spanish Government (ECO2010-22143). The preparation of this manuscript was mostly funded through the Scottish Government Rural Affairs and the Environment Portfolio Strategic Research Programme 2016-2021 (WP 1.4. "Sustainable Management of Natural Assets"). MC gratefully acknowledges the support of the National Science Centre of Poland (Sonata 10, 2015/19/D/HS4/01972). The first author is extremely grateful especially to Prof. Antoni Riera and Dr. Cati Torres (University of the Balearic Islands) for their constructive comments and input at the design stage of the survey and on preliminary versions of this manuscript. In addition, the authors are thankful to the members

\footnotetext{
18 In addition, we found that presenting the outcomes as uncertain increases the preference heterogeneity around 'uncertain' attributes, and increases utility function error term variance, effectively making the respondents' choices appear more random (choice task in an uncertain framework could be perceived by respondents as more difficult; c.f. Czajkowski et al. 2016). Ignoring these effects can lead to misspecification and biased estimates.
} 
of the Social, Economic and Geographical Science group at the James Hutton Institute, the Environmental Economics and Governance research group at the University of St. Andrews and the Land, Environment, Economics and Policy (LEEP) Institute at the University of Exeter, as well as to the participants to the 2017 Envecon Conference and 23rd Annual Conference of the European Association of Environmental and Resource Economists for their valuable comments on earlier versions of this paper. The authors would also like to thank the editor and two anonymous reviewers for their constructive feedback during the review process.

Open Access This article is distributed under the terms of the Creative Commons Attribution 4.0 International License (http://creativecommons.org/licenses/by/4.0/), which permits unrestricted use, distribution, and reproduction in any medium, provided you give appropriate credit to the original author(s) and the source, provide a link to the Creative Commons license, and indicate if changes were made.

\section{Appendix}

See Tables 5, 6, 7, 8 and 9. 


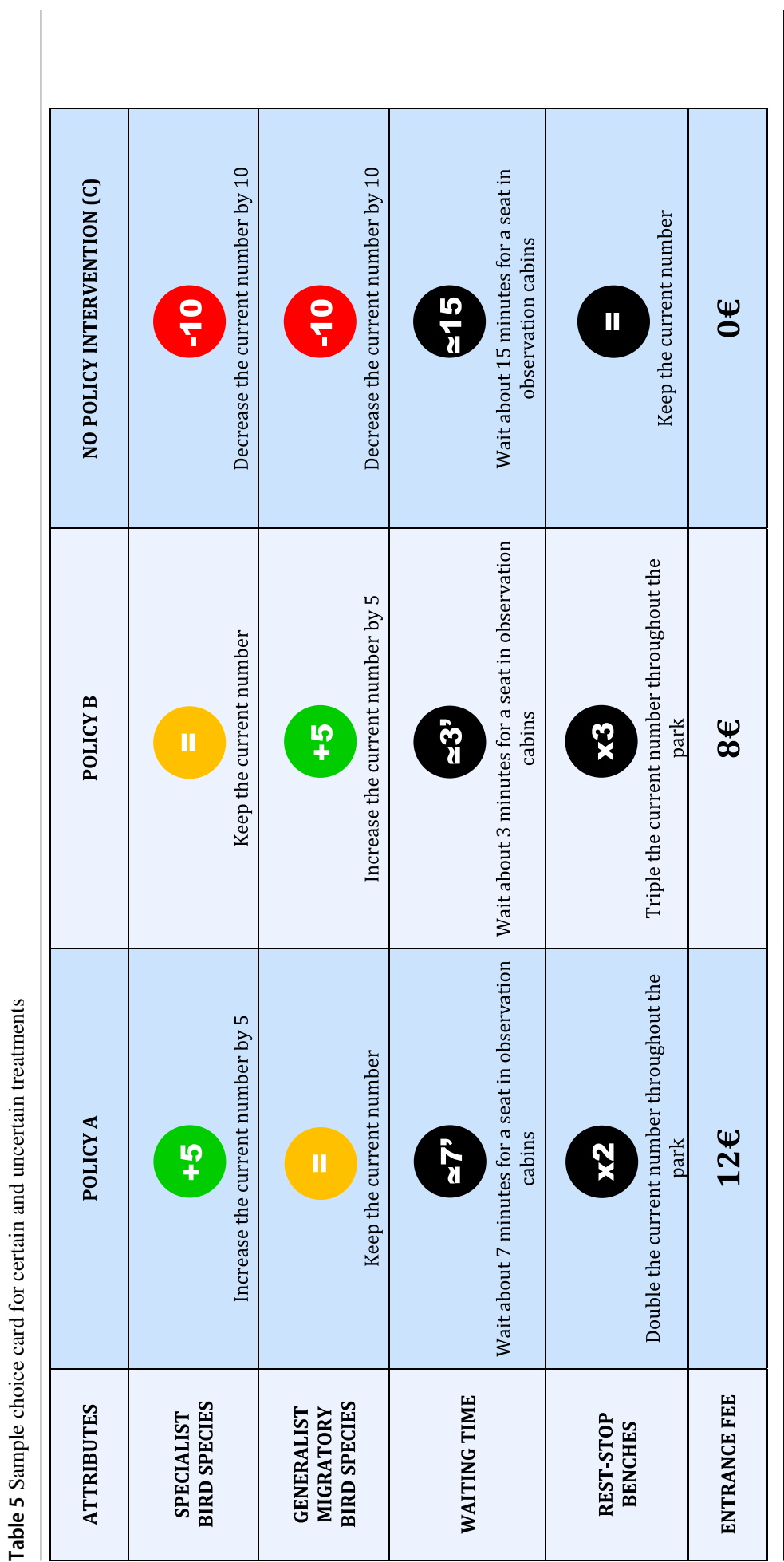




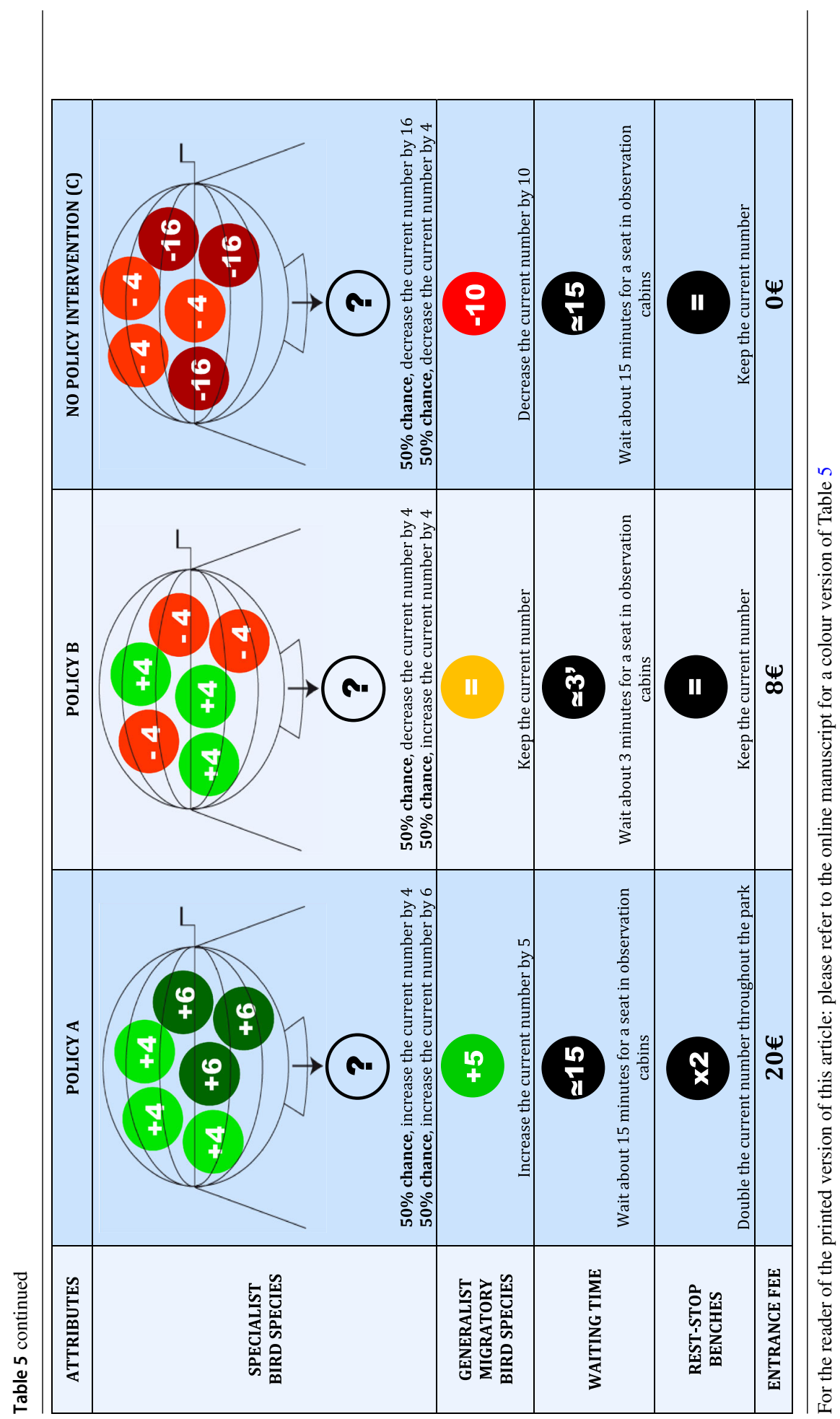




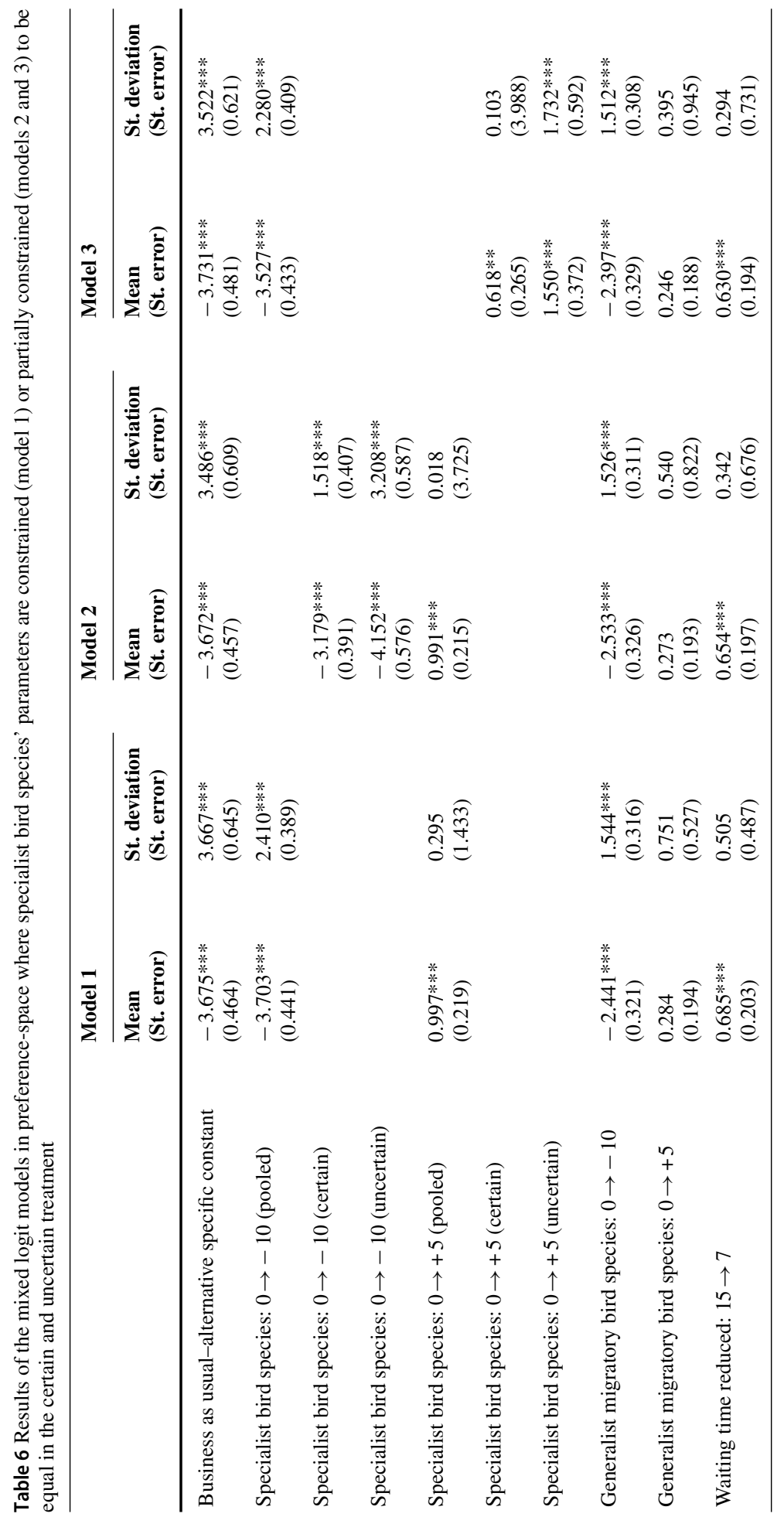




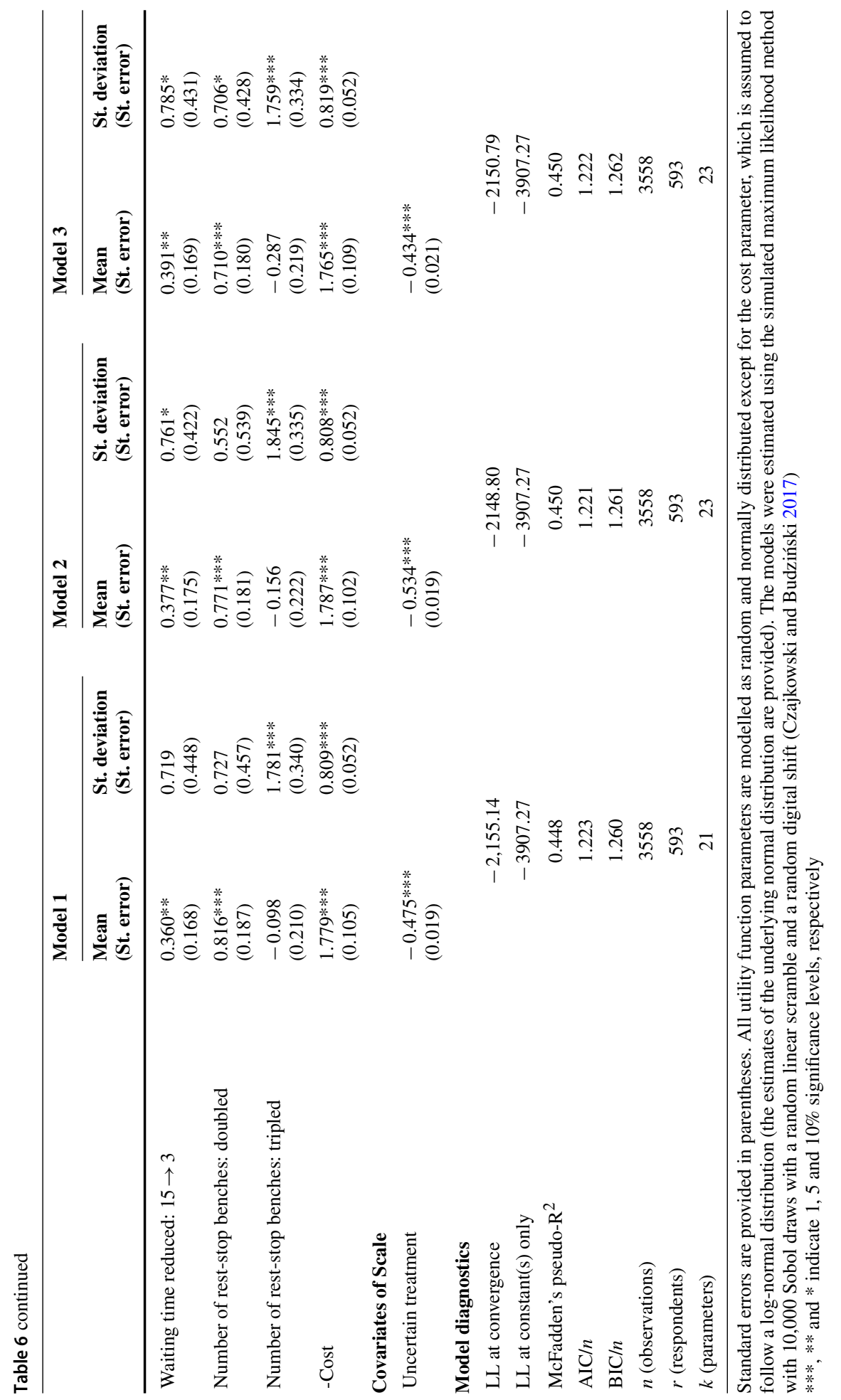


Table 7 The random regret minimization model results—an alternative way to explain respondents' choices

\begin{tabular}{|c|c|}
\hline & $\begin{array}{l}\text { Coefficient } \\
\text { (St. error) }\end{array}$ \\
\hline Business as usual—alternative specific constant & $\begin{array}{l}-0.345 * * * \\
(0.008)\end{array}$ \\
\hline Specialist bird species: $0 \rightarrow-10$ (certain) & $\begin{array}{l}-0.861 * * * \\
(0.020)\end{array}$ \\
\hline Specialist bird species: $0 \rightarrow-10$ (uncertain) & $\begin{array}{l}-0.923 * * * \\
(0.000)\end{array}$ \\
\hline Specialist bird species: $0 \rightarrow+5$ (certain) & $\begin{array}{l}-0.083 * * * \\
(0.000)\end{array}$ \\
\hline Specialist bird species: $0 \rightarrow+5$ (uncertain) & $\begin{array}{l}0.342^{* * * *} \\
(0.000)\end{array}$ \\
\hline Generalist migratory bird species: $0 \rightarrow-10$ & $\begin{array}{l}-0.485^{* * *} \\
(0.017)\end{array}$ \\
\hline Generalist migratory bird species: $0 \rightarrow+5$ & $\begin{array}{l}-0.043 \\
(0.028)\end{array}$ \\
\hline Waiting time reduced: $15 \rightarrow 7$ & $\begin{array}{l}0.263 * * * \\
(0.000)\end{array}$ \\
\hline Waiting time reduced: $15 \rightarrow 3$ & $\begin{array}{l}0.165 * * * \\
(0.002)\end{array}$ \\
\hline Number of rest-stop benches: doubled & $\begin{array}{l}0.073 * * * \\
(0.000)\end{array}$ \\
\hline Number of rest-stop benches: tripled & $\begin{array}{l}-0.138 * * * \\
(0.014)\end{array}$ \\
\hline -Cost & $\begin{array}{l}1.203 * * * \\
(0.000)\end{array}$ \\
\hline \multicolumn{2}{|l|}{ Scale parameters } \\
\hline$\mu$ & $\begin{array}{l}43.923 * * * \\
(0.644)\end{array}$ \\
\hline \multicolumn{2}{|l|}{ Model diagnostics } \\
\hline LL at convergence & -2820.26 \\
\hline LL at constant(s) only & -3908.86 \\
\hline McFadden's pseudo-R ${ }^{2}$ & 0.279 \\
\hline $\mathrm{AIC} / n$ & 1.593 \\
\hline $\mathrm{BIC} / n$ & 1.615 \\
\hline$n$ (observations) & 3558 \\
\hline$r$ (respondents) & 593 \\
\hline$k$ (parameters) & 13 \\
\hline
\end{tabular}

The RRM models were estimated using the Matlab codes available from www.advancedrrmmodels.com $* * *, * *$ and $*$ indicate 1,5 and $10 \%$ significance levels, respectively. Standard errors provided in parentheses 


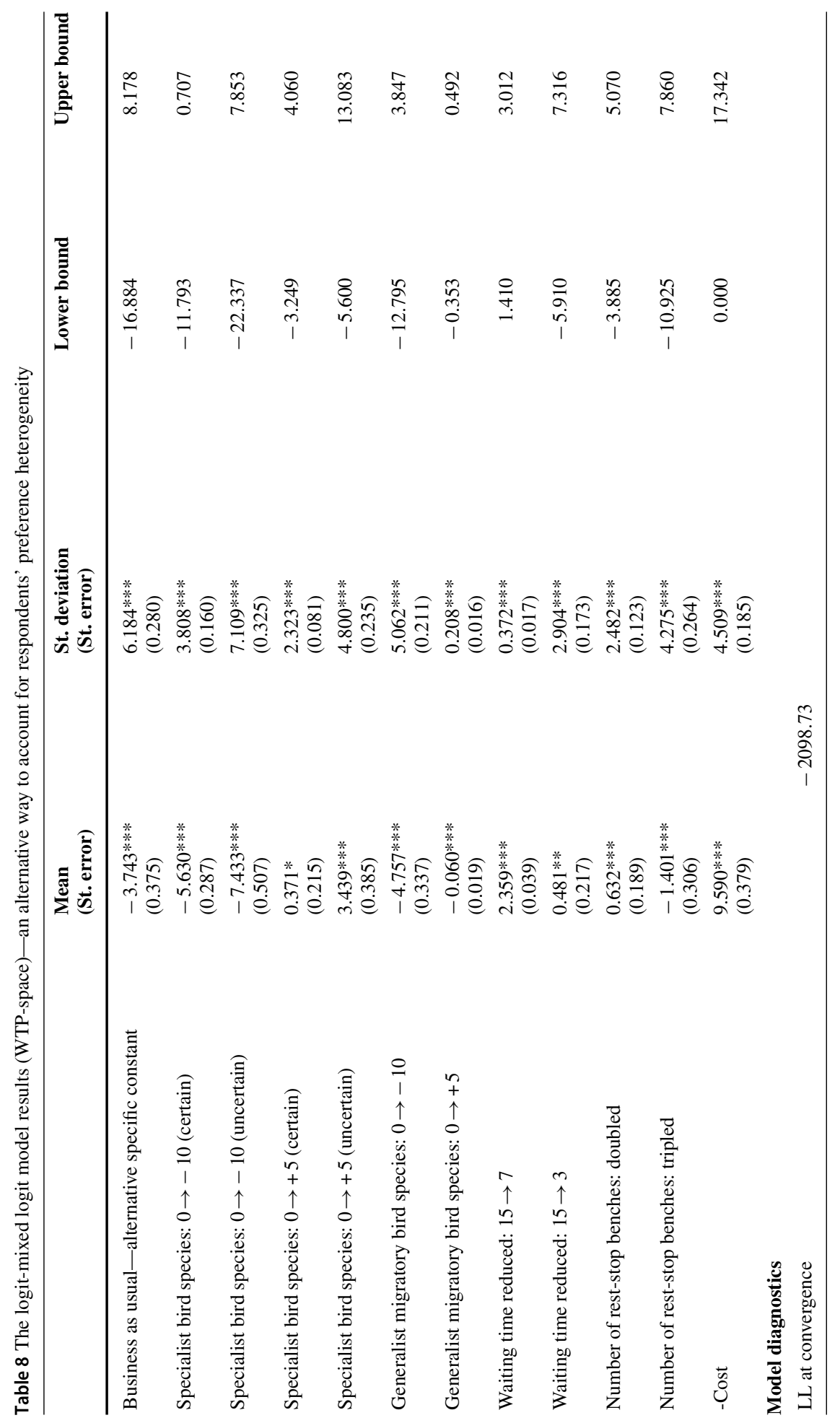




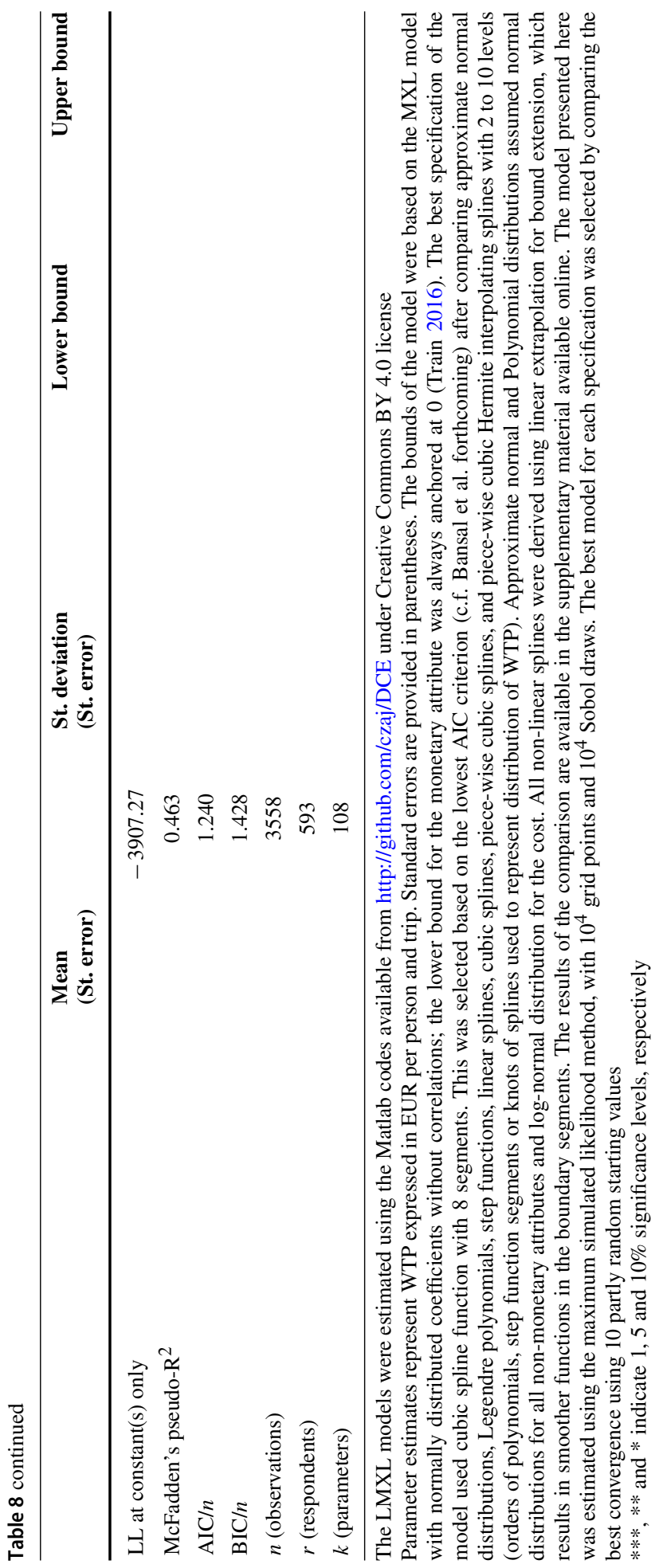




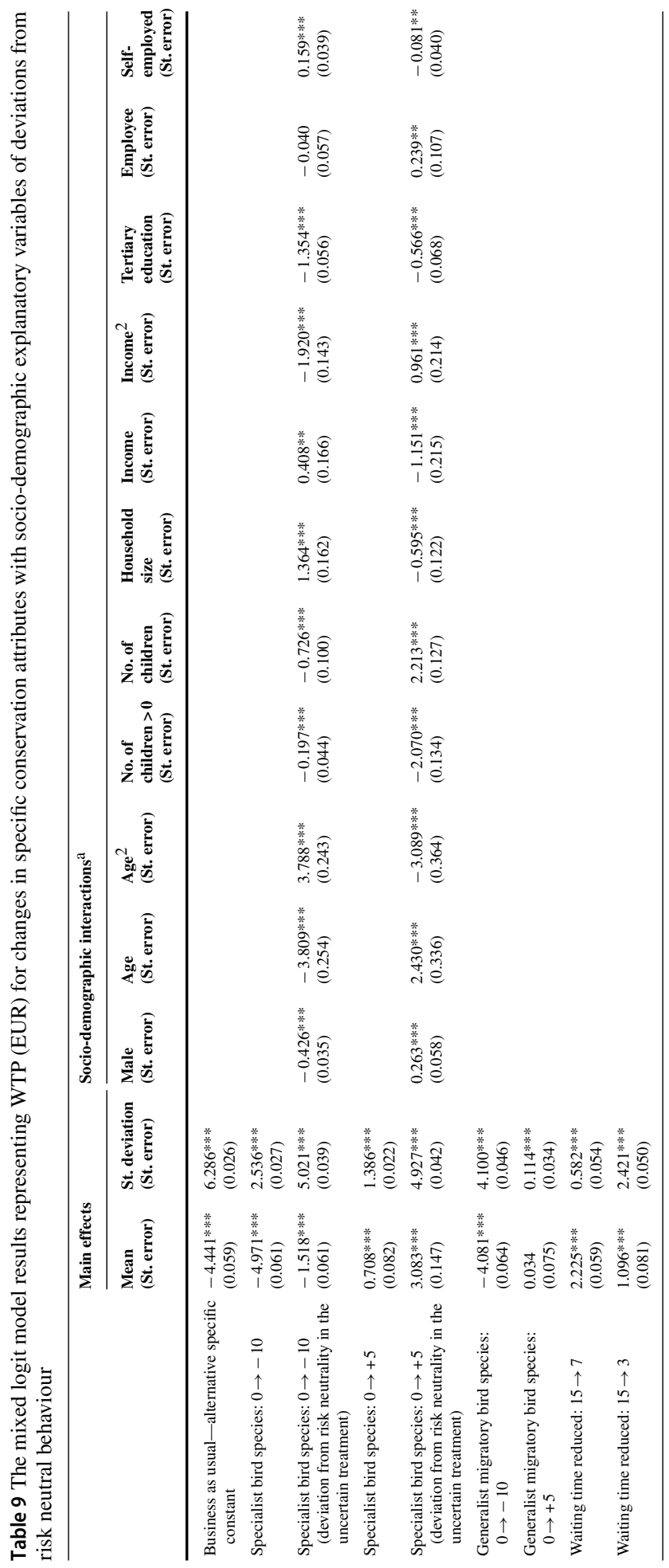




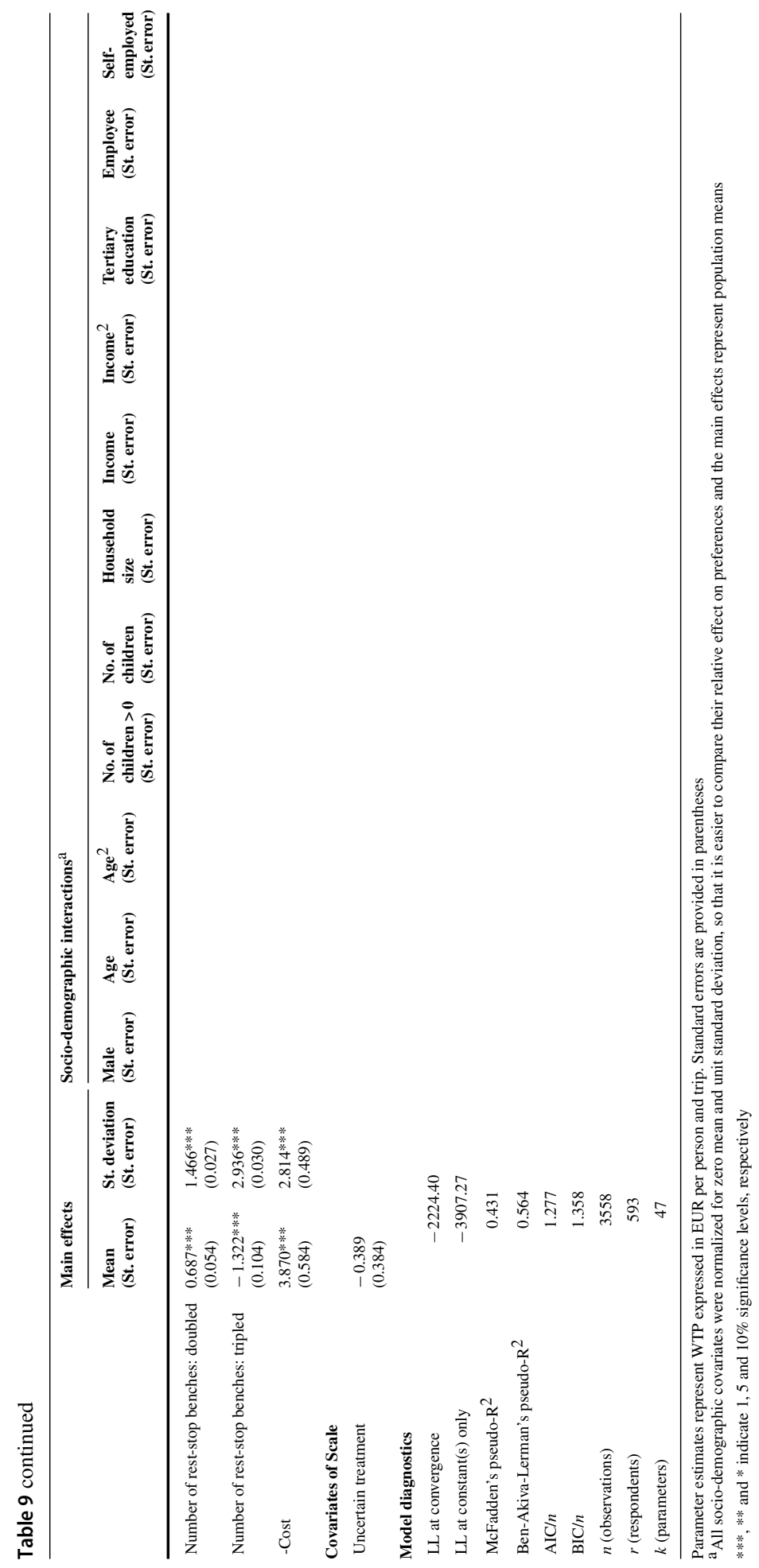




\section{References}

Ananda J, Herath G (2005) Evaluating public risk preferences in forest land-use choices using multi-attribute utility theory. Ecol Econ 55(3):408-419

Andersson M, Gong P (2010) Risk preferences, risk perceptions and timber harvest decisions — an empirical study of nonindustrial private forest owners in northern Sweden. For Policy Econ 12(5):330-339

Bansal P, Daziano RA, Achtnicht M, forthcoming. Comparison of parametric and semiparametric representations of unobserved preference heterogeneity in logit models. J Choice Model

Barnett J, Breakwell GM (2001) Risk perception and experience: hazard personality profiles and individual differences. Risk Anal 21(1):171-177

Bartczak A, Mariel P, Chilton S, Meyerhoff J (2015) The impact of latent risk preferences on valuing the preservation of threatened lynx populations in Poland. Austr J Agri Econ 60:284-306

Bartczak A, Chilton S, Czajkowski M, Meyerhoff J (2017) Gain and loss of money in a choice experiment. The impact of financial loss aversion and risk preferences on willingness to pay to avoid renewable energy externalities. Energy Econ 65:326-334

Bateman I, Munro A, Rhodes B, Starmer C, Sugden R (1997) A test of the theory of reference-dependent preferences. Q J Econ 479-505

Bateman I, Kahneman D, Munro A, Starmer C, Sugden R (2005) Test competing models of loss aversion: an adversarial collaboration. J Public Econ 89:1561-1580

Blais A-R, Weber EU (2006) A domain-specific risk-taking (DOSPERT) scale for adult populations. Judgm Decis Mak 1(1):33-47

Brooks N (2003) Vulnerability, risk and adaptation: a conceptual framework. Tyndell Centre for Climatic Change Research Working Paper 38

Caliendo M, Fossen F, Kritikos A (2010) The impact of risk attitudes on entrepreneurial survival. J Econ Behav Organ 76(1):45-63

Carson RT, Czajkowski M (2014) The discrete choice experiment approach to environmental contingent valuation. In: Hess S, Daly A (eds) Handbook of choice modelling. Edward Elgar, Northampton

Charness G, Gneezy U (2012) Strong evidence for gender differences in risk taking. J Econ Behav Organ 83(1):50-58

Charness G, Gneezy U, Imas A (2013) Experimental methods: eliciting risk preferences. J Econ Behav Organ $87: 43-51$

Czajkowski M, Budziński W (2017) Simulation error in maximum likelihood estimation of discrete choice models. Working Paper 18/2017 (247), Department of Economics, University of Warsaw, Poland

Czajkowski M, Hanley N, LaRiviere J (2014) The effects of experience on preferences: theory and empirics for environmental public goods. Am J Agr Econ 97(1):333-351

Czajkowski M, Hanley N, LaRiviere J (2016) Controlling for the effects of information in a public goods discrete choice model. Environ Resour Econ 63(3):523-544

de Jonge J, van Trijp H, Renes RJ, Frewer L (2007) Understanding consumer confidence in the safety of food: its two-dimensional structure and determinants. Risk Anal 27(3):729-740

Devictor V, Julliard R, Jiguet F (2008) Distribution of specialist and generalist species along spatial gradients of habitat disturbance and fragmentation. Oikos 117(4):507-514

Ding X, Hartog J, Sun Y (2010) Can we measure individual risk attitudes in a survey? IZA Discussion Paper 4807

Dohmen T, Falk A, Huffman D, Sunde U, Schupp J, Wagner GG (2011) Individual risk attitudes: measurement, determinants and behavioral consequences. J Eur Econ Assoc 9(3):522-550

Eckel CC, Grossman PJ (2008) Forecasting risk attitudes: An experimental study using actual and forecast gamble choices. J Econ Behav Organ 68(1):1-17

Ekelund J, Johansson E, Järvelin M-R, Lichtermann D (2005) Self-employment and risk aversion-evidence from psychological test data. Labour Econ 12(5):649-659

Faccioli M, Riera A, Torres CM (2015) Valuing the recreational benefits of wetland adaptation to climate change: a trade-off between species' abundance and diversity. Environ Manage 55(3):550-563

Figner B, Weber EU (2011) Who takes risks when and why?: Determinants of risk taking. Curr Dir Psychol Sci 20:211-216

Fooken J, Schaafner M (2016) The role of Psychological and Physiological Factors in Decision Making under Risk in a Dilemma. Front Behav Neurosci 10(2):1-10

Glenk K, Colombo S (2011) How sure can you be? A framework for considering delivery uncertainty in benefit assessments based on stated preference methods. J Agr Econ 62(1):25-46

Gong B, Yang C-L (2012) Gender differences in risk attitudes: Field experiments on the matrilineal Mosuo and the patriarchal Yi. J Econ Behav Organ 83(1):59-65 
Griffin RJ, Dunwoody S, Neuwirth K (1999) Proposed model of the relationship of risk information seeking and processing to the development of preventive behaviors. Environ Res 80(2):S230-S245

Guiso L, Paiella M (2004) The role of risk aversion in predicting individual behaviour. Temi di discussione del servizio studi della Banca d'Italia Nr. 546

Hartog J, Ferrer-i-Carbonell A, Jonker N (2002) Linking Measured Risk Aversion to Individual Characteristics. Kyklos 55(1):3-26

Heal G, Millner A (2014) Uncertainty and decision-making in climate change economics. Rev Environ Econ Policy 8(1):120-137

Hensher DA, Rose JM, Greene WH (2015) Applied choice analysis, 2nd edn. Cambridge University Press, Cambridge

Holmes TP, Adamowicz WL, Carlsson F (2017) Choice experiments. In: Champ PA, Boyle KJ, Brown TC (eds) A primer on nonmarket valuation. Springer, Amsterdam

Holt CA, Laury SK (2005) Risk aversion and incentive effects: new data without order effects. Am Econ Rev 95(3):902-904

IPCC (2014) Climate change 2014: impacts, adaptation and vulnerability. Contribution of Working Group II to the Fifth Assessment Report of the Intergovernmental Panel on Climate Change. Cambridge University Press, Cambridge, United Kingdom and New York, USA

Isik M (2006) An experimental analysis of impacts of uncertainty and irreversibility on willingness to pay. Appl Econ Lett 13(2):67-72

Johansson P-O (1989) Valuing public goods in a risky world: an experiment. In: Folmer H, van Ierland E (eds) Valuation methods and policy making in environmental economics. Elsevier Science Publisher, Amsterdam

Kahneman D, Tversky A (1979) Prospect theory: an analysis of decision under risk. Econometrica 47(2):263-292

Koundouri P, Stithou M, Kougea E, Ala-aho P, Eskelinen E, Karjalainen T, Klove B, Pulido M, Reinikainen K, Rossi PM (2014) The contribution of nonuse values to inform the management of groundwater systems: the Rokua esker, Northern Finland. In: Nunes PALD, Kumar P, Dedeurwaerdere T (eds) Handbook on the economics of ecosystem services and biodiversity. Edward Elgar Publishing, Cheltenham

Larue B, West GE, Singbo A, Tamini LD (2017) Risk aversion and willingness to pay for water quality: the case of non-farm rural residents. J Environ Manage 197:296-304

Lipkus I (2007) Numeric, verbal, and visual formats of conveying health risks: suggested best practices and future recommendations. Med Decis Mak 27:696-713

Lundhede TH, Jacobsen JB, Hanley N, Strange N, Thorsen BJ (2015) Incorporating outcome uncertainty and prior outcome beliefs in stated preferences. Land Econ 91(2):296-316

Macmillan D, Hanley N, Buckland S (1996) A contingent valuation study of uncertain environmental gains. Scot J Polit Econ 43:519-533

Mata R, Josef AK, Samanez-Larkin GR, Hertwig R (2011) Age differences in risky choice: a meta-analysis. Ann N Y Acad Sci 1235:18-29

McFadden D (1974) Conditional logit analysis of qualititative choice behaviour. In: Zarembka P (ed) Frontiers in econometrics. Academic Press, New York, pp 105-142

McFadden D, Train K (2000) Mixed MNL models for discrete response. J Appl Econom 15(5):447-470

Nguyen Y, Noussair CN (2014) Risk aversion and emotions. Pacific economic review 19(3):296-312

Nicholson W, Snyder C (2015) Intermediate Microeconomics and its application. Cengage Learning, Boston (USA)

Nicholson N, Soane E, Fenton-O’Creevy M, Willman P (2005) Personality and domain-specific risk taking. J Risk Res 8(2):157-176

Pannenberg M (2007) Risk aversion and reservation wages. IZA Discussion Paper No. 2806

Patt A, Dessai S (2005) Communicating uncertainty: lessons learned and suggestions for climate change assessment. CR Geosci 337(4):425-441

Pindyck RS (2007) Uncertainty in environmental economics. Rev Environ Econ Policy 1(1):45-65

Riddel M (2012) Comparing risk preferences over financial and environmental lotteries. J Risk Uncertain 45:135-157

Roberts DC, Boyer TA, Lusk JL (2008) Preferences for environmental quality under uncertainty. Ecol Econ 66:584-593

Rolfe J, Windle J (2015) Do respondents adjust their expected utility in the presence of an outcome certainty attribute in a choice experiment? Environ Resour Econ 60:125-142

Rothschild M, Stiglitz JE (1970) Increasing risk: a definition. J Econ Theory 2:225-243

Sato M, Riddiford N (2008) A preliminary study of the Odonata of S'Albufera Natural Park, Mallorca: status, conservation priorities and bio-indicator potential. J Insect Conserv 12(5):539-548 
Scarpa R, Thiene M, Train K (2008) Utility in Willingness to pay space: a tool to address confounding random scale effects in destination choice to the Alps. Am J Agri Econ 90(4):994-1010

Schonberg T, Fox CR, Poldrack RA (2011) Mind the gap: bridging economic and naturalistic risk-taking with cognitive neuroscience. Trends Cogn Sci 15(1):11-19

Torres C, Faccioli M, Riera A (2017) Waiting or acting now? The effect on willingness-to-pay of delivering inherent uncertainty information in choice experiments. Ecol Econ 131:231-240

Train KE (2009) Discrete choice methods with simulation. Cambridge University Press, New York

Train K (2016) Mixed logit with a flexible mixing distribution. J Choice Model 19:40-53

Train KE, Weeks M (2005) Discrete choice models in preference space and willingness-to-pay space. In: Scarpa R, Alberini A (eds) Applications of simulation methods in environmental and resource economics. Springer, Dordrecht, pp 1-16

van Cranenburgh S, Guevara CA, Chorus CG (2015) New insights on random regret minimization models. Transport Res A-Pol 74:91-109

Wärneryd K-E (1996) Risk attitudes and risky behaviour. J Econ Psychol 17:749-770

Weber EU, Blais A-R, Betz NE (2002) A domain-specific risk-attitude scale: measuring risk perceptions and risk behaviors. J Behav Decis Making 15(4):263-290

Wielgus J, Gerber LR, Sala E, Bennett J (2009) Including risk in stated-preference economic valuations: Experiments on choices for marine recreation. J Enviro Manage 11:3401-3409 